\title{
\begin{tabular}{l|l} 
Mibraries & DSpace@MIT
\end{tabular}
}

\author{
MIT Open Access Articles
}

Mathematical analysis of oxygen transfer through polydimethylsiloxane membrane between double layers of cell culture channel and gas chamber in microfluidic oxygenator

The MIT Faculty has made this article openly available. Please share how this access benefits you. Your story matters.

Citation: Kim, Min-Cheol, Raymond H. W. Lam, Todd Thorsen, and H. Harry Asada.

"Mathematical Analysis of Oxygen Transfer through Polydimethylsiloxane Membrane Between Double Layers of Cell Culture Channel and Gas Chamber in Microfluidic Oxygenator." Microfluid Nanofluid 15, no. 3 (February 1, 2013): 285-296.

As Published: http://dx.doi.org/10.1007/s10404-013-1142-8

Publisher: Springer Berlin Heidelberg

Persistent URL: http://hdl.handle.net/1721.1/103106

Version: Author's final manuscript: final author's manuscript post peer review, without publisher's formatting or copy editing

Terms of use: Creative Commons Attribution-Noncommercial-Share Alike 


\section{Mathematical Analysis of Oxygen Transfer through Polydimethylsiloxane Membrane between Double Layers of Cell Culture Channel and Gas Chamber in Microfluidic Oxygenator}

5 Min-Cheol Kim ${ }^{1,2, \uparrow, *}$, Raymond H. W. Lam ${ }^{1,3, \dagger}$, Todd Thorsen ${ }^{1, *}$, and H. Harry Asada ${ }^{1,2}$

${ }^{1}$ Department of Mechanical Engineering, Massachusetts Institute of Technology, Cambridge, MA 02139

$10 \quad{ }^{2}$ BioSystem \& Micromechanics (BioSyM) IRG, Singapore-MIT Alliance for Research \& Technology, Singapore, 117543

${ }^{3}$ Department of Mechanical and Biomedical Engineering, City University of Hong Kong, Hong Kong, China

$15 \dagger$ Authors are equally contributed to this work.

* To whom correspondence should be addressed: mincheol@mit.edu, thorsen@mit.edu 


\begin{abstract}
For successful cell culture in microfluidic devices, precise control of the microenvironment, including gas transfer between the cells and the surrounding medium, is exceptionally important. The work is motivated by a PDMS microfluidic oxygenator chip for mammalian cell culture suggesting that the speed of the oxygen transfer may vary depending on the thickness of a PDMS membrane or the height of a fluid channel. In this paper, a model is presented to describe the oxygen transfer dynamics in the PDMS microfluidic oxygenator chip for mammalian cell culture. Theoretical studies were carried out to evaluate the oxygen profile within the multilayer device, consisting of a gas reservoir, a PDMS membrane, a fluid channel containing growth media, and a cell culture layer. The corresponding semi-analytical solution was derived to evaluate dissolved oxygen concentration within the heterogeneous materials, and was found to be in good agreement with the numerical solution. Additionally, a separate analytical solution was obtained to investigate the oxygen pressure drop $(O P D)$ along the cell layer due to oxygen uptake of cells, with experimental validation of the $O P D$ model carried out using human umbilical vein endothelial cells cultured in a PDMS microfluidic 15 oxygenator. Within the theoretical framework, the effects of several microfluidic oxygenator design parameters were studied, including cell type and critical device dimensions.
\end{abstract}




\section{Introduction}

Oxygen transport in biological culture has been essential to many microfluidic applications, including cell-based assays (Brischwein M et al. 2003; Tourovskaia A et al. 2005; Kane BJ et al. 2006; Wang Z et al. 2007; Lam LHW et al. 2009; Polinkovsky M et al. 2009), bioreactors (Szita N et al. 2005; De Bartolo L et al. 2006; Sud D et al. 2006), and tissue engineering (Radisic M et al. 2006a). Tissue engineering often involves moderate/long-term mammalian cell growth within culture platforms or scaffolds to obtain multi-dimensional structures for in vivo implantation (Radisic M et al. 2006b; Toh YC et al. 2007). However, the relatively low solubility of oxygen in aqueous solutions $(\sim 0.2 \mathrm{mM} / \mathrm{atm})$ is often insufficient to satisfy the demand of dense cell cultures

$10 \quad\left(10^{7}-10^{9}\right.$ cells $\left./ \mathrm{ml}\right)$ via passive diffusion alone.

Miniaturization of the culture environment combined with an external oxygen supply is an effective approach to increase cell culture oxygenation rates, as diffusion time is proportional to the square of the path length. Researchers have developed a number of oxygenation techniques for microfluidic devices (Beebe DJ et al. 2002; Leclerc E et al. 2004; Zhang ZY et al. 2006; Higgins JM et al. 2007), which can be mainly categorized as unified and separating types, determined by whether the medium is treated as the oxygen source. For the unified approach, a single culture microchannel is utilized for both oxygenation and nutrient supply, implementing a flowing medium with a defined level of dissolved oxygen (DO) at the channel entry. However, as the cells proliferate, increasing oxygen demands can only be met by increasing the flow rate to levels that potentially introduce unfavorable levels of shear stress on the culture. In contrast, the separating type approach, which has been demonstrated as an effective oxygenation methodology for tissue-scale engineering applications (Radisic M et al. 2006b), utilizes devices fabricated in an oxygen-permeable material with the injection of oxygen through distinct microchannels proximal to the culture region. As such, separating type devices create a local constant concentration source of oxygen that rapidly diffuses into the surrounding medium for cellular uptake.

As a structural material of microfluidic devices, polydimethylsiloxane (PDMS) has been recognized as an ideal material for tissue culture due to its gas permeability and excellent molding properties (McDonald JC et al. 2000). Its high permeability to oxygen ( 620 Barrer for untreated PDMS (Houston KS et al. 2002); 1 Barrer $=7.5005 \times 10^{-18} \mathrm{~m}^{2} \cdot \mathrm{s}^{-1} \cdot \mathrm{Pa}^{-1}$ ) suggests that a separating type 
oxygenation scheme could be easily implemented via passive diffusion in an ambient environment (Szita N et al. 2005; De Bartolo L et al. 2006). However, the typical PDMS device thickness ( 5 mm) makes passive oxygenation impractical, with an effective diffusion time (top surface of device to confined microchannels) of $\sim 26$ min. Using multilayer soft lithography (Thorsen $\mathrm{T}$ et al. 2002), the diffusion time can be greatly reduced with an internal membrane oxygenator (Roy P et al. 2001), consisting of an overhead control channel containing flowing air or a defined oxygen/nitrogen mixture separated from the flow channel containing cells and culture medium by a thin PDMS membrane of thickness $\sim 10-100 \mu \mathrm{m}$ that enables rapid gas diffusion (Vollmer AP et al. 2005). Many separating type microfluidic devices have been recently developed for mammalian and bacterial cell culture,

10 including a PDMS-based chip with a gas perfusion network designed for parallel cell culture (Kane BJ et al. 2006), and oxygenation systems with integrated differential oxygen/nitrogen mixers for long-term cellular growth analysis under differential DO concentrations (Lam LHW et al. 2009; Polinkovsky M et al. 2009).

In multilayer separation type microfluidic oxygenators, oxygen molecular transport across the 15 liquid-solid interfaces (i.e. medium-PDMS and medium-cell) can be modeled with two types of boundary conditions, 1) the mass flux of oxygen and 2) continuous oxygen partial pressure $\left(\mathrm{pO}_{2}\right)$ at the interfaces governed by Henry's law. As a preliminary approximation for the medium-cell interface, it is reasonable to ignore the discrete interfacial oxygen level by assuming that the $\mathrm{pO}_{2}$ and oxygen concentration are both continuous across the interface as most cells contain $>70 \%$ of water (Pathi P et al. 2005; Radisic M et al. 2005; Park J et al. 2006; Radisic M et al. 2006a). Nevertheless, even when the mass fluxes of oxygen on both material surfaces are identical, with no net oxygen transfer across the interfaces, there is a still an abrupt change in oxygen concentration, especially between medium and PDMS, due to the different solubility (or Henry's law coefficients) of the materials (Zanzotto A et al. 2002; Patton JN and Palmer AF 2006). In solving the oxygen profiles, governing equations for convection-diffusion mass transfer can be converted to differential equations for $\mathrm{pO}_{2}$, which have been previously applied to the analysis of oxygen and nutrient transport between red blood cells and lumen tissue in blood capillaries (Masterton WL and Hurley CN 2002).

In this paper, we propose an approximated semi-analytical solution for the general 2-D gas diffusion problem of stacked materials by combining the single layer solutions for materials with individual gas diffusivity and solubility properties using predefined velocity profiles and DO levels. 
Furthermore, an analytical solution for the estimated oxygen pressure drop $(O P D)$ between the cell monolayer and gas reservoir is derived by taking into consideration of different layers of heterogeneous materials including tissue or cells, culture medium and the PDMS membrane. In particular, this technique is applied to a separating type microfluidic oxygenation device to investigate the performance of oxygen transfer from the gas channel to the cell culture monolayer under different device configurations.

\section{Models}

\section{Governing equations of Oxygen Transfer in Microfluidic Oxygenator}

The mass transfer for a typical microfluidic oxygenator (Zanzotto A et al. 2002; Vollmer AP et al. 2005; Kane BJ et al. 2006; Lam RHW et al. 2009; Polinkovsky M et al. 2009) with low microchannel aspect ratios (height/width) can be modeled as a 2-D geometry (Figure 1), with the double layer channel structure of upper oxygen gas reservoir and lower cell culture chamber separated by a thin oxygen-permeable PDMS membrane. During culture oxygenation, a convective medium flow is imposed from the inlet of cell culture chamber to provide fresh nutrients for the growth of cells located on the lower chamber surface. The governing equations for the transient DO concentrations in cell layer $\left(c_{1}\right)$, medium $\left(c_{2}\right)$ and PDMS membrane $\left(c_{3}\right)$ are expressed as follows,

$$
\begin{aligned}
& \frac{\partial c_{1}(x, y, t)}{\partial t}=D_{1} \frac{\partial^{2} c_{1}(x, y, t)}{\partial y^{2}}-O C R(x, y, t), \text { for } 0 \leq y \leq H_{1} \\
& \frac{\partial c_{2}(x, y, t)}{\partial t}=D_{2} \frac{\partial^{2} c_{2}(x, y, t)}{\partial y^{2}}-u(y) \frac{\partial c_{2}(x, y, t)}{\partial x}, \text { for } H_{1} \leq y \leq H_{1}+H_{2} \\
& \frac{\partial c_{3}(x, y, t)}{\partial t}=D_{3} \frac{\partial^{2} c_{3}(x, y, t)}{\partial y^{2}}, \text { for } H_{1}+H_{2} \leq y \leq H_{1}+H_{2}+H_{3}
\end{aligned}
$$

where $H_{1}$ is the cell layer thickness, $H_{2}$ is the effective channel height or culture medium layer thickness, $H_{3}$ is the PDMS membrane thickness separating the gas and medium channels, $t$ is time, $x$ and $y$ are the horizontal and vertical positions, respectively, and $D_{i}$ and $S_{i}(i=1,2,3)$ are the diffusivity and solubility of their corresponding materials (cell, medium and PDMS, respectively) summarized in Table 1. $\operatorname{OCR}(x, y, t)$ is the oxygen consumption rate of cells based on Michaelis-Menten kinetics (Allen JW and Bhatia SN 2003):

$$
\operatorname{OCR}(x, y, t)=\frac{V_{\max } \rho_{\text {cell }} c_{1}(x, y, t)}{K_{m}+c_{1}(x, y, t)}
$$

where $V_{\max }$ is the maximum respiration rate per cell (e.g. $4 \times 10^{-17} \mathrm{~mole} / \mathrm{cell} / \mathrm{s}$ for human umbilical 
vein endothelial cells (HUVEC) and $3.8 \times 10^{-16} \mathrm{~mole} / \mathrm{cell} / \mathrm{s}$ for hepatocyte cells (HC) (Allen JW and Bhatia SN 2003))), $\rho_{\text {cell }}\left(=\rho^{*}{ }_{\text {cell }} / H_{1}\left[\right.\right.$ cells/ml]; where $\rho^{*}$ cell is the surface cell coverage [cells $\left.\left./ \mathrm{cm}^{2}\right]\right)$ is the volumetric cell density, and $K_{m}\left(=S_{1} K_{m}^{\prime}\right.$; where $K_{m}^{\prime}$ is Michaelis-Menten constant) is the specific oxygen concentration at which the respiration rate decreases to one half of its maximum value. Depending on cell types, Eq. 4 can have different Michaelis-Menten constants, $K_{m}^{\prime}$ (e.g. $0.5 \mathrm{mmHg}$ for HUVEC and and $5.6 \mathrm{mmHg}$ for HC (Allen JW and Bhatia SN 2003)). In Eqs. 1 - 3, the diffusive terms along $x$ direction were neglected due to the low aspect ratio of structure (the governing equations still represent most of the channel region where $x>>$ $H_{1}+H_{2}+H_{3}$ ), while the convective term in Eq. 2 was retained to capture the effect of DO in inlet medium $\left(c_{2}(0, y, t)=0[\mu \mathrm{M}]\right.$, for $\left.H_{1} \leq y \leq H_{1}+H_{2}\right)$. The oxygen concentrations are initially set to be constant over the material domains, i.e. $c_{1}(x, y, t)=C_{1}=220.25[\mu \mathrm{M}], c_{2}(x, y, t)=C_{2}=0[\mu \mathrm{M}]$, and $c_{3}(x, y, t)=C_{3}=249.38[\mu \mathrm{M}]$ at $t=0$.

The bottom glass substrate is oxygen-impermeable (no mass flux into the bottom glass substrate (Eq. 5)). Applying Henry's law, $\mathrm{pO}_{2}$ at interfaces between heterogeneous materials should be continuous (Eqs. 6, 8) (Poulsen L et al. 2003), while the mass flux of oxygen is balanced at the interfaces $\left(y=H_{1}\right.$ and $H_{1}+H_{2}$ (Eqs. 7, 9)) Hence, the boundary conditions (for $t>0$ ) of Eqs. $1-3$ are

$$
\begin{aligned}
& \frac{\partial c_{1}}{\partial y}(x, y, t)=0, \text { at } y=0 \\
& \frac{c_{1}(x, y, t)}{S_{1}}=\frac{c_{2}(x, y, t)}{S_{2}} \text {, at } y=H_{1} \\
& D_{1} \frac{\partial c_{1}}{\partial y}(x, y, t)=D_{2} \frac{\partial c_{2}}{\partial y}(x, y, t), \text { at } y=H_{1} \\
& \frac{c_{2}(x, y, t)}{S_{2}}=\frac{c_{3}(x, y, t)}{S_{3}} \text {, at } y=H_{1}+H_{2} \\
& D_{2} \frac{\partial c_{2}}{\partial y}(x, y, t)=D_{3} \frac{\partial c_{3}}{\partial y}(x, y, t), \text { at } y=H_{1}+H_{2} \\
& c_{3}(x, y, t)=S_{3} p_{g}, \text { at } y=H_{1}+H_{2}+H_{3} .
\end{aligned}
$$

Under continuous flow of oxygen through the gas channel, the $\mathrm{pO}_{2}$ on the upper surface of the PDMS membrane is modeled as constant (Eq. 10), equal to that of the supplied gas.

\section{Dimensionless Form of the Governing Equations and Boundary Conditions}

To generalize the problem of oxygen transfer among multiple heterogeneous materials, governing equations and boundary conditions for the transient $\mathrm{pO}_{2}$ (Eqs. 1-10) were converted to the 
corresponding dimensionless forms (Eqs. 15 - 23) (Poulsen L et al. 2003). The new dimensionless variables $g_{1}, g_{2}, g_{3}, m_{1}, m_{2}$, and $m_{3}$ are introduced as

$$
\begin{gathered}
g_{1}(\xi, \psi, \tau)=\frac{P_{g}}{P_{i n}}-\frac{c_{1}(x, y, t)}{S_{1} P_{i n}} \\
g_{2}(\xi, \psi, \tau)=\frac{P_{g}}{P_{i n}}-\frac{c_{2}(x, y, t)}{S_{2} P_{i n}} \\
g_{3}(\xi, \psi, \tau)=\frac{P_{g}}{P_{i n}}-\frac{c_{3}(x, y, t)}{S_{3} P_{i n}} \\
m_{1}(\xi, \psi, \tau)=\frac{\alpha_{1}^{2} D a}{\beta_{1}} \frac{P_{g}-g_{1} P_{i n}}{\bar{K}_{m} P_{i n}+\delta_{1}\left(P_{g}-g_{1} P_{i n}\right)}, m_{2}(\xi, \psi, \tau)=-\frac{P e \gamma_{1}}{\gamma_{2}} u^{*} \frac{\partial g_{2}}{\partial \xi} \text { and } m_{3}(\xi, \psi, \tau)=0
\end{gathered}
$$

where $\xi(=x / L)$ and $\psi\left(=y / H_{c}\right)$ are the dimensionless lengths of the $x$ and $y$ coordinates, $L$ and $H_{c}(=$ $\left.H_{1}+H_{2}\right)$ are the length and height of medium channel, respectively, $\tau\left(=D_{2} t / H_{c}{ }^{2}\right)$ indicates the dimensionless diffusion time, $P_{i n}=0.001$ atm is the $\mathrm{pO}_{2}$ at the inlet of medium channel, $P_{\mathrm{g}}=0.1995$ atm (under the supply of air with $\left.5 \% \mathrm{CO}_{2}\right)$ is the $\mathrm{pO}_{2}$ along gas reservoir, $\mathrm{Da}\left(=V_{\max } \rho^{*}{ }_{\text {cell }} H_{c} / S_{2} P_{\text {in }}\right.$ $D_{2}$ ) is the dimensionless Damkohler number which represents the ratio of the overall oxygen uptake rate of cell layer to the diffusive flux of oxygen in medium, $\bar{K}_{m}\left(=K_{m} / S_{2} P_{i n}\right)$ is the dimensionless Michaelis-Menten constant, $\delta_{1}\left(=S_{1} / S_{2}\right)$ is the ratio of solubility between cell layer and medium, $\delta_{2}$ $\left(=S_{2} / S_{3}\right)$ is the ratio of solubility between medium and PDMS membrane, $\mathrm{Pe}\left(=U \mathrm{H}_{2} / \mathrm{D}_{2}\right)$ is the Peclet number along medium layer where $U$ is mean velocity in the medium layer, $\gamma_{1}\left(=H_{c} / H_{2}\right)$ is the ratio between medium channel height and effective channel height, $\gamma_{2}\left(=L / H_{c}\right)$ is the aspect ratio of culture channel, $\gamma_{3}\left(=H_{3} / H_{2}\right)$ is the thickness ratio between PDMS membrane and medium layer, $u^{*}$ $\left(=6 U\left(\beta_{2}-\psi\right)\left(\psi-\beta_{1}\right)\right)$ is the dimensionless fully developed velocity profile in the medium layer with interface boundaries along $\psi$ at $\beta_{1}\left(=H_{1} / H_{\mathrm{c}}\right)$ and $\beta_{2}=1$. Substituting the dimensionless parameters into Eqs. $1-3$ yields

$$
\begin{aligned}
& \alpha_{1}^{2} \frac{\partial g_{1}}{\partial \tau}=\frac{\partial^{2} g_{1}}{\partial \psi^{2}}+m_{1}, \text { for } \beta_{0} \leq \psi \leq \beta_{1} \\
& \alpha_{2}^{2} \frac{\partial g_{2}}{\partial \tau}=\frac{\partial^{2} g_{2}}{\partial \psi^{2}}+m_{2}, \text { for } \beta_{1} \leq \psi \leq \beta_{2} \\
& \alpha_{3}^{2} \frac{\partial g_{3}}{\partial \tau}=\frac{\partial^{2} g_{3}}{\partial \psi^{2}}+m_{3}, \text { for } \beta_{2} \leq \psi \leq \beta_{3}
\end{aligned}
$$

where $\alpha_{1}=\sqrt{D_{2} / D_{1}}, \alpha_{2}=1, \alpha_{3}=\sqrt{D_{2} / D_{3}}, \beta_{0}=0$, and $\beta_{3}=\left(H_{1}+H_{2}+H_{3}\right) / H_{c}$. The boundary conditions of mass fluxes at the interfaces (Eqs. $5-10$ ) for $\tau>0$ are converted to the dimensionless form as follows, 


$$
\begin{aligned}
& \frac{\partial g_{1}}{\partial \psi}(\xi, 0, \tau)=0 \\
& g_{1}\left(\xi, \beta_{1}, \tau\right)=g_{2}\left(\xi, \beta_{1}, \tau\right) \\
& \frac{\delta_{1}}{\alpha_{1}^{2}} \frac{\partial g_{1}}{\partial \psi}\left(\xi, \beta_{1}, \tau\right)=\frac{\partial g_{2}}{\partial \psi}\left(\xi, \beta_{1}, \tau\right) \\
& g_{2}\left(\xi, \beta_{2}, \tau\right)=g_{3}\left(\xi, \beta_{2}, \tau\right)
\end{aligned}
$$

\section{Semi-analytical solution}

The solution of dimensionless oxygen profiles for all material layers $\left(g_{i}, i=1,2\right.$ and 3$)$ were derived semi-analytically (as described in the Electronic Supplementary Information (ESI)) and coupled with their spatial derivatives, $\partial g_{i}(\xi, \psi, \tau) / \partial \psi$, at the interfacial boundaries (Mulholland GP and Cobble MH 1972; Fredman TP 2003) (see Eq. S31). The analytical solution for 1-D convection-diffusion problems was extended to $2-\mathrm{D}$ by coupling $g_{i}(\xi, \psi, \tau)$ in $\xi$ direction, updating the term $\partial g_{i} / \partial \xi$ in Eq. 16 with the finite difference approximation $\partial g_{2}\left(\xi_{j+1}, \psi, \tau_{0}\right) / \partial \xi \approx\left[g_{2}\left(\xi_{j+1}, \psi, \tau_{0}\right)-g_{2}\left(\xi_{j}, \psi, \tau_{0}\right)\right] /\left(\xi_{j+1}-\xi_{j}\right)$ at the dimensionless priori simulation time $\left(\tau_{0}\right)$. Afterwards, the dimensionless oxygen profiles, $g_{i}$, were converted to the oxygen concentrations of the physical problem, $c_{i}(x, y, t)$.

The spatial derivative of $g_{i}(\xi, \psi, \tau)$ can be written as

$$
\begin{array}{r}
\frac{\partial g_{i}(\xi, \psi, \tau)}{\partial \psi}=Q_{i}(\xi, \psi, \Delta \tau) G_{i}(\xi, \tau)+R_{i}(\xi, \psi, \Delta \tau) G_{i+1}(\xi, \tau)+P_{i}\left(\xi, \psi, \tau_{0}, \Delta \tau\right), \\
i=1,2,3 ; 0 \leq \xi \leq 1 ; \beta_{i} \leq \psi \leq \beta_{i+1}
\end{array}
$$

20 where $\Delta \tau$ is the dimensionless simulation time step; $P_{i}\left(\xi, \psi, \tau_{0}, \Delta \tau\right), Q_{i}(\xi, \psi, \Delta \tau)$ and $R_{i}(\xi, \psi, \Delta \tau)$ are the coefficients in the linear equation (Calculation of the coefficients is described in the ESI); $G_{i}\left(\xi, \tau_{0}\right)$ and $G_{i+1}\left(\xi, \tau_{0}\right)$ are the boundary values at the bottom and top sides of material $i$, respectively, and can be obtained by solving the linear algebra equations in the matrix form $A(\xi) \cdot X(\xi)=b(\xi)$ ), which is readily solved line-by-line along the channel axial direction $(0 \leq \xi \leq 1)$ using tri-diagonal matrix algorithm (TDMA) (Conte SD and deBoor C 1972) with Eq. 25.

\section{Procedures for obtaining semi-analytical}


The general procedure for solving the $\mathrm{pO}_{2}$ profile over a stack of different heterogeneous materials in the presence of fully developed fluid flow are summarized as follows:

1. Specify the number of material layers $\left(N=3\right.$ in this work), select the final time $\left(t_{\text {final }}\right)$ and number of time steps $\left(N_{\text {time }}\right)$ for the calculation of concentration profile over different materials, calculate the dimensionless final time $\left(\tau_{\text {final }}=t_{\text {final }} \times D_{2} / H_{c}{ }^{2}\right)$ and dimensionless time step $(\Delta \tau$ $\left.=\tau_{\text {final }} / N_{\text {time }}\right)$, and set $\tau_{0}=0$ and $\tau_{1}=\tau_{0}+\Delta \tau$.

2. Specify the vertical and horizontal grid numbers of each layer depending on the corresponding layer dimensions.

3. Find the eigenvalues spectrum, $\lambda_{i, n}$ for $i=1,2, \ldots, N$, of each material.

4. Compute $A(\xi)$ and $b(\xi)$ along to the axial direction of channels $(0 \leq \xi \leq 1)$.

5. Set $G_{i}\left(\xi, \tau_{0}\right)=G_{i}\left(\xi, \tau_{1}\right)$ for $i=1,2, \ldots, N+1$ and $0 \leq \xi \leq 1$, and solve the linear matrix equations $(A(\xi) \cdot X(\xi)=b(\xi))$ to update the dimensionless concentration $G_{i}\left(\xi, \tau_{0}\right)$ at material interfaces. Afterward, substitute $G_{i}\left(\xi, \tau_{0}\right)$ and $G_{i}\left(\xi, \tau_{1}\right)$ with updated $P_{i}\left(\xi, \psi, \tau_{0}, \Delta \tau\right), Q_{i}(\xi, \psi, \Delta \tau)$ and $R_{i}(\xi, \psi, \Delta \tau)$ into Eq. 24 to calculate the current spatial distribution of $g_{i}(\xi, \psi, \tau)$ for $\psi_{i} \leq \psi \leq \psi_{i+1}$ and $0 \leq \xi \leq 1$.

6. If $\tau_{1}<\tau_{\text {final }}$, set $\tau_{0}=\tau_{1}$ and $\tau_{1}=\tau_{0}+\Delta \tau$, and go to step 5 .

7. Convert $g_{i}(\xi, \psi, \tau)$ to $c_{i}(x, y, t)$.

(Detailed descriptions of the calculation of $A(\xi), b(\xi), \lambda_{i, n}, P_{i}\left(\xi, \psi, \tau_{0}, \Delta \tau\right), Q_{i}(\xi, \psi, \Delta \tau)$ and $R_{i}(\xi, \psi, \Delta \tau)$ are available as ESI.)

20

$$
\begin{aligned}
& A(\xi)=\left(\begin{array}{cccc}
Q_{1}(\xi, 0, \Delta \tau) & R_{1}(\xi, 0, \Delta \tau) & 0 & 0 \\
\frac{\delta_{1}}{\alpha_{1}^{2}} Q_{1}\left(\xi, \beta_{1}, \Delta \tau\right) & \frac{\delta_{1}}{\alpha_{1}^{2}} R_{1}\left(\xi, \beta_{1}, \Delta \tau\right)-Q_{2}\left(\xi, \beta_{1}, \Delta \tau\right) & -R_{2}\left(\xi, \beta_{1}, \Delta \tau\right) & 0 \\
0 & \alpha_{3}^{2} \delta_{2} Q_{2}\left(\xi, \beta_{2}, \Delta \tau\right) & \alpha_{3}^{2} \delta_{2} R_{2}\left(\xi, \beta_{2}, \Delta \tau\right)-Q_{3}\left(\xi, \beta_{2}, \Delta \tau\right) & -R_{3}\left(\xi, \beta_{2}, \Delta \tau\right) \\
0 & 0 & 0 & 1
\end{array}\right), \\
& b(\xi)=\left(\begin{array}{c}
-P_{1}\left(\xi, 0, \tau_{0}, \Delta \tau\right) \\
-\frac{\delta_{1}}{\alpha_{1}^{2}} P_{1}\left(\xi, \beta_{1}, \tau_{0}, \Delta \tau\right)+P_{2}\left(\xi, \beta_{1}, \tau_{0}, \Delta \tau\right) \\
-\alpha_{3}^{2} \delta_{2} P_{2}\left(\xi, \beta_{2}, \tau_{0}, \Delta \tau\right)+P_{3}\left(\xi, \beta_{2}, \tau_{0}, \Delta \tau\right) \\
0
\end{array}\right) \text { and } X(\xi)=\left(\begin{array}{c}
G_{1}(\xi, \tau) \\
G_{2}(\xi, \tau) \\
G_{3}(\xi, \tau) \\
G_{4}(\xi, \tau)
\end{array}\right) .
\end{aligned}
$$

\section{Oxygen pressure drop along the cell culture monolayer}

For high density of cell cultures at the monolayer, the total oxygen uptake can be significant, inducing a local oxygen pressure drop $(O P D)$ along the cell culture monolayer. Considering the steady 
state oxygen transfer in the fully-developed region in an oxygenator described in Figure 1, the mass fluxes of oxygen across each material layer are identical, as oxygen consumption within the heterogeneous material stack is zero. Such mass fluxes of oxygen can be expressed as

$$
q=\frac{D_{3} S_{3}}{H_{3}}\left(P_{g}-P_{2-3}\right)=\frac{2 D_{2} S_{2}}{H_{2}}\left(P_{2-3}-P_{2 b}\right)=\frac{2 D_{2} S_{2}}{H_{2}}\left(P_{2 b}-P_{\text {cell }}\right)
$$

where $P_{2-3}$ is the $\mathrm{pO}_{2}$ at the interface between PDMS membrane and medium channel, $P_{2 b}$ is the bulk $\mathrm{pO}_{2}$ in medium, and $P_{\text {cell }}$ is the $\mathrm{pO}_{2}$ along top cell surface. If we correlate $q$ with the cellular oxygen uptake rate at the equilibrium state, $q$ can be written as

$$
q=\left.D_{1} \frac{\partial c_{1}}{\partial y}\right|_{y=H_{\text {cell }}}=\int_{0}^{H_{1}} \frac{V_{\max } \rho_{\text {cell }} c_{1}}{K_{m}+c_{1}} d y \approx \frac{V_{\max } \rho_{\text {cell }} c_{1}}{\mathrm{~S}_{1} K_{m}^{\prime}+c_{1}} H_{1}=\frac{V_{\max } \rho_{\text {cell }}^{*} P_{\text {cell }}}{K_{m}^{\prime}+P_{\text {cell }}}
$$

where $\rho_{\text {cell }}^{*}\left(=\rho_{\text {cell }} H_{1}\right)$ is the cell density [cells $/ \mathrm{cm}^{2}$ ]. In particular, it is assumed that the $\mathrm{pO}_{2}$ in a thin the dimensionless oxygen pressure $\operatorname{drop}\left(O P D=\left(P_{g}-P_{\text {cell }}\right) / P_{g}\right)$ between the top cell surface (or cell layer) and gas reservoir can be simplified in following form:

$$
\begin{aligned}
& O P D=\frac{P_{g}-P_{\text {cell }}}{P_{g}}=\frac{1}{2}(1+A+B)-\frac{1}{2} \sqrt{(1-A-B)^{2}+4 A}, \\
& A=\frac{K_{m}^{\prime}}{P_{g}} \text { and } B=\frac{V_{\max } \rho_{\text {cell }}^{*}}{P_{g}}\left(\frac{H_{3}}{D_{3} S_{3}}+\frac{H_{2}}{D_{2} S_{2}}\right)=\frac{P_{i n} D a}{P_{g} \gamma_{1}}\left(\alpha_{3}^{2} \delta_{2} \gamma_{3}+1\right)
\end{aligned}
$$

where the value of $A$ is cell-type specific, with a unique Michaelis-Menten constant, while $B$ lumps all of the other general parameters into a single value. The surface plot of $O P D$ (Figure 2) shows that the gradient of the function $O P D$ with respect to $B$ decreases gradually for $0 \leq B \leq 1$ as the variable $A$ increases from 0 to 0.03 , indicating that the cell type with lower $K_{m}{ }_{m}(\sim 0.5 \mathrm{mmHg})$ will result in a slightly larger $O P D$ than one with higher $K_{m}{ }_{m}(\sim 5.6 \mathrm{mmHg})$ under the equivalent total oxygen uptake rate of cells $\left(V_{\max } \rho^{*}\right.$ cell $)$ and identical culture conditions, i.e. environment factors and device configuration.

\section{Validation Experiment of Oxygen Pressure Drop}

Device design and fabrication

Single layer PDMS $\left(H_{2}=200 \mu \mathrm{m}, H_{3}=5 \mathrm{~mm}\right)$ devices containing three culture channels described in Figure 3a,b were fabricated to verify the OPD induced by the oxygen uptake of HUVEC, while the double layer structure of oxygenator was not used because the $\sim 100-800 \mu \mathrm{m}$ membrane 
thickness $\left(H_{3}\right)$ induced only negligible $O P D$ (data not shown). The PDMS channel was fabricated by pour 10:1 PDMS monomer/harder mixture on a Si/SU-8 mold defining the medium channel dimensions. Prior to $\mathrm{O}_{2}$ plasma bonding to the PDMS substrate, the glass slide deposited with oxygen-sensitive platinum (II) octaethylporphine ketone (PtOEPK)-polystyrene sensors was fabricated per the diffusion time validation experiment, except that the HF (hydrofluoric acid) etching step was skipped and an extra layer of $\sim 8 \mu \mathrm{m}$ PDMS was spin-coated on a glass deposited with a 4 $\mu \mathrm{m}$ thick sensor layer to create and additional barrier to between the cells and the PtOEPK dye, whose cytotoxic effects are unknown. PtOEPK has no oxygen consumption for measurement, so there is still no mass flux of oxygen along the bottom cell surface. The fully developed $\mathrm{pO}_{2}$ profile along cell, medium and top PDMS substrate is the same as the model described in Figure 1.

\section{Cell culture}

HUVECs (Lonza) were cultured in Dulbecco's Modified Eagle Media (DMEM, purchased from Gibco) containing $10 \%$ fetal bovine serum. The cell line was manipulated into a new culture flask pre-coated with $20 \mathrm{mg} / \mathrm{ml}$ gelatin (Sigma) in 1x PBS under sterile tissue culture hoods and cultured in a $5 \% \mathrm{CO}_{2}$ humidified incubator at $37{ }^{\circ} \mathrm{C}$. Once the cells were confluent, they were trypsinized $(0.25$ $\%$ in EDTA) and passaged at a 1:5 sub-culture ratio.

\section{Experimental procedures}

Each oxygen sensor along the microchannels was calibrated before the microfluidic devices were sterilized by flushing medium channels with $70 \%$ ethanol followed by baking at $80{ }^{\circ} \mathrm{C}$ for $2 \mathrm{hr}$. After baking, the fluid channels were rinsed with 1x phosphate-buffered saline (PBS), with $\mathrm{pH} 7.4$, and degassed by forcing trapped air through the walls of the gas-permeable oxygenator with pressurized PBS buffer. The PDMS surface along flow channels was subsequently pre-coated with fibronectin (Sigma, $0.1 \% \mathrm{w} / \mathrm{w}$ in $1 \mathrm{x}$ PBS) for $1 \mathrm{hr}$ to promote cell attachment. Excess fibronectin was removed by rinsing with 1x PBS. In preparation for device loading, the cell line was trypsinized, spun down in a centrifuge (1000 rpm, $5 \mathrm{~min}$ ), and reconstituted in fresh DMEM at a target cell density. Cells were then seeded into culture channels by a syringe pump (PicoPlus, Harvard Apparatus) at flow rate 0.05 $\mu \mathrm{l} / \mathrm{min}$ for $10 \mathrm{~min}$ and cultured in a humidified incubator $\left(20 \% \mathrm{O}_{2}\right.$ and $5 \% \mathrm{CO}_{2}$ gas supply) without 
replaced the channels with fresh media, we performed the DO measurement along the sensor layers without medium flow to record the stabilized sensor readings. Microscopic images were also captured at the sensor regions to determine cell density by counting the cells in the images (Figure 3c). Each value of $O P D$, including the results mentioned in the main text, was then calculated from at least three individual measurements. Another measurement on the chip with $1 \mathrm{~cm}$ thick PDMS $\left(H_{3}\right)$ and $200 \mu \mathrm{m}$ tall channel $\left(H_{2}\right)$, containing $3.08 \pm 0.27 \times 10^{4}$ cells $/ \mathrm{cm}^{2}$ of HUVEC, also showed a reasonable experimental $O P D(=0.213 \pm \mathrm{SD} 0.039)$ with respect to the theoretical value $(=0.2223)$ calculated by Eq. 28.

\section{$10 \quad$ Results and Discussion}

\section{Comparison of semi-analytical solution with numerical solution}

The semi-analytical solution (AS) and the assumption of neglecting the horizontal diffusive effect $\partial^{2} c_{i}$ / $\partial x^{2}(i=1,2,3)$ have been validated by the numerical solution (NS) of the full form of governing equations calculated by a commercial simulation software (COMSOL 3.5, MA). The 2-D model of microfluidic oxygenator consists of three material layers (cell $\left(H_{1}=5 \mu \mathrm{m}\right)$, medium $\left(H_{2}=200 \mu \mathrm{m}\right)$ and PDMS $\left.\left(H_{3}=250 \mu \mathrm{m}\right)\right)$, with their corresponding diffusivity and solubility values defined in Table 1. A contour plot of the steady state $\mathrm{pO}_{2}$ profile across the layers $(t=70 \mathrm{~s})$ in the oxygenator for the pre-defined device dimensions and physical parameters is shown in Figure 4a (Other sample $\mathrm{pO}_{2}$ profiles are included in the ESI.) The transient variations of $\mathrm{pO}_{2}$ along the top surface of cellular monolayer at five different times $(5 \mathrm{~s}, 7 \mathrm{~s}, 10 \mathrm{~s}, 30 \mathrm{~s}$ and $70 \mathrm{~s})$ shows good agreement between the AS and NS (Figure 4b).

A sample set of transient dimensionless $\left(g_{i}\right)$ and dimensional $\left(c_{i}\right)$ oxygen concentration profiles (Figure 4c,d) along the three heterogeneous materials at $x=3 \mathrm{~mm}$ illustrates the time response of oxygen transfer across different materials (along $y$ direction) up to the point where the oxygenation profile above the cell culture is fully developed $(t \sim 70 \mathrm{~s})$. In particular, sharp oxygen concentration jumps are observed at the cell boundary and upper wall of the culture medium filled microchannel (Figure 4d), due to the lower solubility of oxygen in water (vs. the cells and PDMS).

It is of interest to investigate spatiotemporal variations of the partial $\mathrm{pO}_{2}$ oxygen under different tissue thicknesses of $10 \mu \mathrm{m}, 20 \mu \mathrm{m}, 50 \mu \mathrm{m}, 100 \mu \mathrm{m}$ and $150 \mu \mathrm{m}$ through the $\mathbf{A S}$ (Figure $\mathbf{S 3}$ ). The 
developing length of $\mathrm{pO}_{2}$ gradually decreases as the cell layer grows in a limited culture channel (constant height: $H_{\mathrm{c}}=H_{1}+H_{2}$ ), inducing an increasing volumetric ratio of cell layer to medium, because the diffusive resistance of $\operatorname{HUVEC}\left(H_{1} / S_{1} D_{1}\right)$ is smaller than that of culture medium $\left(H_{2} / S_{2} D_{2}\right)$. Furthermore, the AS has an advantage over the NS in that it is possible to more accurately calculate spatial derivatives, $\partial g_{i}(\xi, \psi, \tau) / \partial \psi$, at the interfacial boundaries (See equations S30 and S31) using the AS once unknown variables of $\mathrm{X}(\xi)$ are solved. Thereby, the AS leads to predict dependence of the mass flux of oxygen at the interfacial boundaries on various parameters (Figure S1-S3)

\section{Diffusion time of oxygen transfer}

The dynamic response of oxygen transfer in an oxygenator was investigated experimentally (detailed experimental method and results were described in the Electronic Supplementary Information (ESI)), in which the mammalian cell layer was replaced by an oxygen-sensitive PtOEPK-polystyrene layer $(\sim 4 \mu \mathrm{m})$. Although the governing equations for the modified oxygenator have no $O C R$ term (due to zero steady state oxygen consumption of sensor material) and different values of diffusivity $\left(D_{1}=5.7 \times 10^{-7} \mathrm{~cm}^{2} / \mathrm{s}\right)$ and solubility $\left(S_{1}=0.42 \mathrm{mM} / \mathrm{atm}\right)$ for the base layer, the sensor layer has a negligible effect on the diffusion time $(<1.2 \%$ of measured values) because of its thickness $\left(H_{1} \ll<H_{2}\right)$. To investigate the efficiency of oxygenation for the microchannel configuration, the rise time $T_{r}$ (experimental and simulated), defined by the time required for the sensor $\mathrm{pO}_{2}$ to reach $90 \%$ of its stabilized value, was plotted against different channel height and membrane thicknesses

(Figure 5) with reasonable agreement. $T_{r}$ is largely determined by the medium channel height for a thin PDMS membrane, indicated by that $T_{r}$ is relatively insensitive to the change of $H_{3}$ when $H_{3} \ll H_{2}$. On the other hand when $H_{3} \gg H_{2}$, increment of $T_{r}$ is proportional to the square of the PDMS membrane thickness, i.e. $T_{r} \propto H_{3}{ }^{2}$. For the typical configuration of single layer microfluidic devices for cell culture applications, the devices are pre-injected with cells along channels and placed in an incubator. In this case, we may consider the PDMS substrate (thickness $H_{3}: \sim 5 \mathrm{~mm}$ ) as the PDMS membrane of an oxygenator, while the gaseous environment above the PDMS substrate is the gas channel. Considering the device containing microchannel height $\left(H_{2}\right)$ of $\sim 100 \mu \mathrm{m}$ as an example, the rise time $\left(T_{r}\right)$ is then around $3 \mathrm{hr}$, which is apparently a significant obstacle to the culture of aerobic cells by passive diffusion. 


\section{Effective channel length}

To maintain the long-term growth of cells in microfluidic applications especially for confluent cell cultures, continuous medium flow can be applied along microchannels to maintain the cultivation condition with fresh media such that the waste generated from cells can be removed fast enough. We 5 may perform the oxygenated cell culture by continuously flowing fresh medium into the microfluidic oxygenators, in which the flowing fresh medium continuously oxygenates along the microchannels Therefore, the culture medium from the channel inlet has a characteristic entry length to obtain a fully developed oxygen concentration profile. The effective channel length $L^{*}$, which represents the ratio of oxygen diffusion to convection along the medium channel, can be used to determine whether the bulk

of the cell culture chamber region is fully developed $\left(L^{*}>>1\right)$. In the case where both the cell and PDMS layers are sufficiently thin $\left(H_{1} / D_{1} S_{1}\right.$ and $\left.H_{3} / D_{3} S_{3} \gg H_{2} / D_{2} S_{2}\right)$, we let $L^{*}=x / \mathrm{PeH}_{2}$ (Volmer et al. 2005). However, for thick cell and PDMS layers, the variation of $\mathrm{pO}_{2}$ across the culture medium (along the $y$ axis) is often smaller than the corresponding $\mathrm{pO}_{2}$ variation in gas layer, especially when PDMS is thick, requiring $L^{*}$ to be scaled according to the $\mathrm{pO}_{2}$ in the different material layers. The 15 transition region of oxygen diffusion is assumed to be the position where oxygen starts diffusing to the bottom side of the cell layer with negligible $O C R$. Thereby, the oxygen partial pressure gradient across the layers may be related to the diffusive resistance, i.e. $H_{1} / D_{1} S_{1}, H_{2} / D_{2} S_{2}$ and $H_{3} / D_{3} S_{3}$ for cell, medium and PDMS layers, respectively. $L^{*}$ for thick cell and PDMS layers can then be defined as

$$
L^{*}=\frac{x}{P^{2} H_{2}}\left[\left(\frac{H_{1}}{D_{1} S_{1}}+\frac{H_{3}}{D_{3} S_{3}}\right) \frac{D_{2} S_{2}}{H_{2}}+1\right]^{-1} .
$$

Inspection of the dimensionless channel length $\left(L^{*}\right)$ is very useful in assessing whether a channel region is fully developed with respect to the oxygen concentration gradient. Figure 6 show the dimensionless $\mathrm{pO}_{2}$ along cell layer $P_{\text {cell }}^{*}\left(=\left(P_{\text {cell }}-P_{i n)} /\left(P_{g}-P_{i n}\right)\right)\right.$ as a function of $L^{*}$, calculated with $P e=3, D a=3.93$ (with $\rho^{*}{ }_{\text {cell }}=3 \times 10^{4}$ cells $/ \mathrm{cm}^{2}$ ), and $K_{m}^{\prime}=0.5 \mathrm{mmHg}$ for 
different effective channel heights $\left(50<H_{2}<500[\mu \mathrm{m}]\right)$ (Figure 6a) and membrane thickness (50 $<H_{3}<5000[\mu \mathrm{m}]$ ) (Figure 6b). It can be observed that the transition region of $\mathrm{pO}_{2}$ along the cell layer, $P_{\text {cell, }}^{*}$, where the diffusive effect is comparable to the convective one, is around $L^{*} \sim 1 . P^{*}$ cell becomes fully developed as $L^{*}>1$ with a corresponding reduction of $O P D$, i.e. $P_{\text {cell }}^{*} \rightarrow 1-O P D$.

5 In particular, for the case of membrane thickness $5000 \mu \mathrm{m}$ shown in Figure $6 \mathbf{b}$, the $P^{*}{ }_{\text {cell }}$ approaches to a significantly lower level than the other cases as $L^{*}$ because this case of a thick membrane induces relatively larger $O P D(=0.14)$ than all the other cases $(O P D<0.05)$.

The condition $L^{*} \gg 1$ may be challenging in some practical implementations with a thick membrane layer in the typical single layer PDMS devices, a significant cell layer thickness in some 10 tissue culture applications $\left(H_{1}>200 \mu \mathrm{m}\right)$, or a large Peclet number $(P e \sim 99.2$, culture medium velocity $\sim 2.78 \mathrm{~mm} / \mathrm{s}$ along $x$ direction) for the analysis of cell behaviors under high shear stress (Radisic M et al. 2006a). These limitations can be overcome by modifying the oxygenator with extended gas and medium channels prior to the culture chamber to pre-oxygenate the medium.

\section{Experiment for oxygen pressure drop}

Experiments were also performed to verify the $O P D$ of HUVECs along a microchannel (See Figure 3a) with an equivalent structure for fully developed $\mathrm{pO}_{2}$ profile described in Figure 1. HUVECs $\left(H_{1}=5 \mu \mathrm{m}\right)$ with a surface cell coverage of $\sim 10^{3}-10^{4}$ cells $/ \mathrm{cm}^{2}$ were cultured along the microchannel $\left(H_{2}=200 \mu \mathrm{m}\right)$ constrained by the PDMS microchannel $\left(H_{3}=5 \mathrm{~mm}\right)$ with air supplemented with with $5 \% \mathrm{CO}_{2}$ at $37{ }^{\circ} \mathrm{C}\left(\mathrm{pO}_{2}=0.1995 \mathrm{~atm}\right)$. The measured $O P D(0.021 \pm \mathrm{SD}$ $0.009,0.072 \pm 0.026,0.157 \pm 0.030$ and $0.166 \pm 0.033)$ increases with the surface cell coverage $\rho_{\text {cell }}^{*}\left(0.67 \pm 0.05,1.54 \pm 0.12,3.68 \pm 0.21\right.$ and $4.04 \pm 0.29\left[\times 10^{4}\right.$ cells $\left./ \mathrm{cm}^{2}\right]$, respectively) (see Table 2). This result agrees with the analytical solution in Eq. 28 that $O P D$ is proportional to the surface cell coverage $\rho^{*}$ cell for the negligible Michaelis-Menten constant of HUVEC $\left(K_{m}^{\prime} \ll P_{g}\right)$. Furthermore, the experimental maximum cellular respiration rate $V_{\max }\left(\sim 3.12 \times 10^{-17} \mathrm{~mole} / \mathrm{cell} / \mathrm{s}\right)$ is of the same order of magnitude as the analytical value in bulk culture environment $\left(=4 \times 10^{-17}\right.$ mole/cells/s).

\section{Insight of oxygen pressure drop}


sufficient oxygen to cells to avoid an anoxic $\left(\mathrm{pO}_{2} \approx 0 \mathrm{mmHg}\right)$ or hypoxic $\left(\mathrm{pO}_{2} \approx 5-15 \mathrm{mmHg}\right)$ environments leading to necrosis or stress on aerobic mammalian cells (Roy P et al. 2001). However, for cultivation of vascular endothelial cells, maintaing low oxygen level is also important in hypoxia triggers angiogesis by the induction of vascular endothelial growth factor

5 (VEGF) from tumor cells or fibroblast cells, which leads to angiogenic vessel sprouting formation in the extracelluar matrix (ECM) (Germain $S$ et al. 2010). In addition, to maintain an adequate amount of oxygen supply to support confluent cell cultures, the oxygenator should be optimized with respect to the design parameters, including $O P D$ and $T_{r}$. Considering the comparatively large oxygen diffusivity and solubility of PDMS listed in Table 1, the membrane thickness should be 10 minimized to enable rapid gas exchange with the cells (or small $T_{r}$, as mentioned in the previous section) and small $O P D$, which includes parameters $A$ (cell-type dependent) and $B$ as a unified value of the device configuration aforementioned in Eq. 28.

The $O P D$ along the cell culture layer for different cell types (HUVEC and HC), surface cell coverage, channel height $\left(H_{2}\right)$ and PDMS thickness $\left(H_{3}\right)$ is plotted in Figure 7 with $P e=3$, based on a fixed medium flow rate. For the case where $A \ll 0.01$ (e.g. HUVEC culture $\left(K_{m}{ }_{m}=0.5\right.$ $\mathrm{mmHg})$ under the supply of air with $\left.5 \% \mathrm{CO}_{2}\left(\mathrm{pO}_{2}=0.1995 \mathrm{~atm}\right)\right), O P D \sim B$ when $0 \leq B<1$ and $O P D \sim 1$ for $B \geq 1$ as shown in Figure 2. Since $B$ is a linear function of $H_{2}$ and $H_{3}$ when $B<1, B$ increases linearly with respect to incremental thickness changes in $H_{2}$ (Figure 7a) or $H_{3}$ (Figure 7b) as $A<<0.01$, and $B$ is proportional to $\rho^{*}$ cell (observed by the change in gradient of $O P D$ for HUVEC). These results imply that cell growth can induce $O P D$ down to hypoxic levels. The population of cells cultured in microchannels may expand and become confluent during long-term cultivation (i.e. large $V_{\max }$ ), therefore the oxygen consumption of cells may become noticeably higher than the oxygen supply diffused through the PDMS substrate around the microchannels. In this case, the difference between the uptake rate and oxygen diffusion rate results in high $\mathrm{pO}_{2}$ drop between the cell monolayer and the gas channels. On the other hand, the $O P D$ values are also sensitive to cell type. A comparison between HUVEC (surface coverage $\rho^{*}$ cell $=3 \times 10^{5}$ cells $\left./ \mathrm{cm}^{2}\right)$ and $\mathrm{HC}\left(\rho_{\text {cell }}{ }^{*}=3.16 \times 10^{4}\right.$ cells $\left./ \mathrm{cm}^{2}\right)$ with identical $B$ values (equivalent $V_{\max } \rho_{\text {cell }}{ }^{*}$ and identical device geometry as shown in Figure 7) indicates that cell types with different $K_{m}^{\prime}$ and $V_{\max }$ induce distinct $O P D$ responses, dependent on surface cell coverage $\rho^{*}$ cell. Both cell type and surface cell coverage constrain the allowable chamber height in a separating type microfluidic 
oxygenator. In particular, oxygenation with air for $3 \times 10^{5}$ cells $/ \mathrm{cm}^{2}$ of HUVEC requires a cell culture chamber height below $\sim 800 \mu \mathrm{m}$ to avoid generating a hypoxic culture environment as shown in Figure 7a.

Typical cell culture applications using a single layer of channel structures with a $\sim 5 \mathrm{~mm}$ thick overhead PDMS substrate are often considered that the gas exchange (e.g. $\mathrm{O}_{2}$ and $\mathrm{CO}_{2}$ ) is sufficient, yet the corresponding $O P D$ may induce an unfavorable microenvironment for cell growth, as indicated in this study. For instance, the effective diffusion time $\left(=x^{2} / 2 D\right)$ of the typical PDMS device thickness $(\sim 5 \mathrm{~mm})$ is around $26 \mathrm{~min}$, which means that the diffusion resistance becomes relatively high. In this work, we have investigated that the separating type microfluidic oxygenator can be configured to resolve this constrain of gas transfer. The microfluidic can provide the rapid gas exchange through the overhead PDMS membrane (short stabilizing time), minimize $O P D$, and locate the fully developed region $\left(L^{*}>>1\right)$ for the optimal microfluidic cell culture conditions.

A desirable application of gas transport analysis described in this work is the cell cultivation directly on a thin PDMS membrane rather than a gas-impermeable substrate (e.g. glass) underneath cells. Based on Eq. (28), gas exchange of cells is done directly through the PDMS substrate with a great reduction of $O P D$. In addition, for the hypoxia condition, which has been known as a better condition of angiogenic vessel sprouting in a three-dimensional ECM (Vickerman et al. 2008; Farahat WA et al. 2012), it can be easily achieved by increasing thickness of the PDMS layer (>5 mm) or channel height based the $O P D$ analysis.

\section{Conclusions}

The oxygen diffusion process in the typical configuration of separating type microfluidic oxygenator for mammalian cell culture has been investigated through modeling, characterization and experimental validation. The governing equations underlying dynamics of the 2-D multilayer mass transfer process have been converted to a general dimensionless form, for which a semi-analytical solution has also been developed by matching the interfacial boundary conditions of 1-D analytical solutions (along $y$ direction) for single layer heterogeneous materials and numerically approximating over time $(t)$ and channel length ( $x$ direction). The design parameters including $T_{r}, O P D$ and $L^{*}$ have been proposed to quantify the oxygenation performance through characterization of the device 
configuration. The validation of $T_{r}$ and $O P D$ were performed by experiments. General design considerations for microfluidic oxygenators have also been discussed through the parametric studies, e.g. minimizing chamber and membrane thicknesses for small $T_{r}$ and $O P D$, adjusting gas $\mathrm{pO}_{2}$ levels to compensate a large $O P D$, and extending the oxygenation channel upstream of the culture region to establish a fully developed oxygen profile $\left(L^{*}>>1\right)$. This work provides a framework for designing a microfluidic oxygenator, where the miniaturization of such systems for cell physiochemical analysis is of growing interest to the general research community for applications such as drug discovery, personalized medicine and tissue engineering.

\section{Acknowledgements}

The authors thank the Singapore-MIT Alliance of Research and Technology for financial supports of this work. The authors would like to acknowledge the financial supports from Croucher Foundation, Early Career Scheme of Hong Kong Research Grant Council (Project\# RGC124212), and the National Science Foundation under Grant No. EFRI-0735997 and Grant No. STC-0902396. The authors thank Sukhyun Song for his assistance on the HUVEC culture experiment.

\section{References}

Allen JW, Bhatia SN (2003) Formation of steady-state oxygen gradients in vitro - Application to liver zonation. Biotechnol Bioeng 82(3):253-262.

Beebe DJ, Mensing GA, Walker GM (2002) Physics and applications of microfluidics in biology. Annu Rev Biomed Eng 4:261-286.

Brischwein M, Motrescu ER, Cabala R et al (2003) Functional cellular assays with multiparametric silicon sensor chips. Lap Chip 3(4):234-240.

Chakraborty S, Balakotaiah V, Bidani A (2007) Multiscale model for pulmonary oxygen uptake and its application to quantify hypoxemia in hepatopulmonary syndrome. $\mathrm{J}$ theor Biol 244(2):190-207.

Conte SD, deBoor C (1972) Elementary Numerical Analysis. McGraw-Hill, New York.

Cuvelier D, Thery M, Chu YS et al (2007) The universal dynamics of cell spreading. Current Biology 17(8): 694-699. 
De Bartolo L, Salerno S, Morelli S et al (2006) Long-term maintenance of human hepatocytes in oxygen-permeable membrane bioreactor. Biomaterials 27(27):4794-4803.Kane BJ, Zinner MJ, Yarmush ML, Toner M (2006) Liver-specific functional studies in a microfluidic array of primary mammalian hepatocytes. Anal Chem 78(13):4291-4298.

5 Farahat WA, Wood LB, Zervantonakis IK et al (2012) Ensemble Analysis of Angiogenic Growth in Three-Dimensional Microfluidic Cell Cultures. PLOS one 7(5):e37333.

Fredman TP (2003) An analytical solution method for composite layer diffusion problems with an application in metallurgy. Heat and Mass Transfer 39(4):285-295.

Germain S, Monnot C, Muller L, Eichmann A (2010) Hypoxia-driven angiogenesis: role of tip cells and extracellular matrix scaffolding. Current Opinion in Hematology 17(3):245-251.

Higgins JM, Eddington DT, Bhatia SN, Mahadevan L (2007) Sickle cell vasoocclusion and rescue in a microfluidic device. Proc Natl Acad Sci USA 104(51):20496-20500.

Houston KS, Weinkauf DH, Stewart FF (2002) Gas transport characteristics of plasma treated poly (dimethylsiloxane) and polyphosphazene membrane materials. $\mathrm{J}$ membrane Sci 205(1-2):103-112.

Kane BJ, Zinner MJ, Yarmush ML, Toner M (2006) Liver-specific functional studies in a microfluidic array of primary mammalian hepatocytes. Anal Chem 78(13):4291-4298.

Lam RHW, Kim MC, Thorsen T (2009) Culturing Aerobic and Anaerobic Bacteria and Mammalian Cells with a Microfluidic Differential Oxygenator. Anal Chem 81(14):5918-5924.

Leclerc E, Sakai Y, Fujii T (2004) Microfluidic PDMS (polydimethylsiloxane) bioreactor for large-scale culture of hepatocytes. Biotechnol Prog 20(3):750-755.

Masterton WL, Hurley CN (2002) Chemistry: Principles and Reactions. Thomson Books/Cole, Belmont.

McDonald JC, Duffy DC, Anderson JR et al (2000) Fabrication of microfluidic systems in poly(dimethylsiloxane). Electrophoresis 21(1):27-40.

Mulholland GP, Cobble MH (1972) Diffusion through composite media. Int J Heat Mass Transfer 15(1):147-160.

Park J, Bansal T, Pinelis M, Maharbiz MM (2006) A microsystem for sensing and patterning oxidative microgradients during cell culture. Lab Chip 6(5):611-622. 
Pathi P, Ma T, Locke BR (2005) Role of nutrient supply on cell growth in bioreactor design for tissue engineering of hematopoietic cells. Biotechnol Bioeng 89(7):743-758.

Patton JN, Palmer AF (2006) Numerical simulation of oxygen delivery to muscle tissue in the presence of hemoglobin-based oxygen carriers. Biotechnol Prog 22(4):1025-1049.

5 Polinkovsky M, Gutierrez E, Levchenko A, Groisman A (2009) Fine temporal control of the medium gas content and acidity and on-chip generation of series of oxygen concentrations for cell cultures. Lab Chip 9(8):1073-1084.

Poulsen L, Zebger I, Tofte P et al (2003) Oxygen diffusion in bilayer polymer films. J Phys Chem B. 107(50):13885-13891.

10 Radisic M, Deen W, Langer R, Vunjak-Novakovic G (2005) Mathematical model of oxygen distribution in engineered cardiac tissue with parallel channel array perfused with culture medium containing oxygen carriers. Am J Physiol Heart Circ Physiol 288(3):H1278-H1289.

Radisic M, Malda J, Epping E, Geng W, Langer R, Vunjak-Novakovic G (2006a) Oxygen gradients correlate with cell density and cell viability in engineered cardiac tissue. Biotechnol Bioeng 93(2):332-343.

Radisic M, Park H, Chen F et al (2006b) Biomirnetic approach to cardiac tissue engineering: Oxygen carriers and channeled scaffolds. Tissue Eng 12(8):2077-2091.

Roy P, Baskaran H, Tilles AW, Yarmush ML, Toner M (2001) Analysis of oxygen transport to hepatocytes in a flat-plate microchannel bioreactor. Ann Biomed Eng 29(11):947-955.

Shiku H, Saito T, Wu CC et al (2006) Oxygen permeability of surface-modified poly(dimethylsiloxane) characterized by scanning electrochemical microscopy. Chemistry Letters 35(2):234-235.

Sud D, Mehta G, Mehta K et al (2006) Optical imaging in microfluidic bioreactors enables oxygen monitoring for continuous cell culture. J Biomed Optics 11(5):050504.

Szita N, Boccazzi P, Zhang Z et al (2005) Development of a multiplexed microbioreactor system for high-throughput bioprocessing. Lab Chip 5(8): 819-826.

Tan JL, Tien J, Pirone M, Gray DS et al (2003) Cells lying on a bed of microneedles: An approach to isolate mechanical force. Proc Natl Acad Sci USA 100(4):1484-1489.

Thorsen T, Maerkl SJ, Quake SR (2002) Microfluidic large-scale integration. Science 298(5593):580-584. 
Toh YC, Zhang C, Zhang J et al (2007) A novel 3D mammalian cell perfusion-culture system in microfluidic channels. Lab Chip 7(3):302-309.

Tourovskaia A, Figueroa-Masot X, Folch A (2005) Differentiation-on-a-chip: A microfluidic platform for long-term cell culture studies. Lab Chip 5(1):14-19.

5 Valeur B, Brochon JC (2001) New trends in fluorescence spectroscopy: applications to chemical and life. Springer, New York, pp. 236.

Vickerman V, Blundo J, Chung S, Kamm R (2008) Design, fabrication and implementation of a novel multi-parameter control microfluidic platform for three-dimensional cell culture and real-time imaging. Lab Chip 8(9):1468-1477.

10 Vollmer AP, Prostein RF, Gilbert R, Thorsen T (2005) Development of an integrated microfluidic platform for dynamic oxygen sensing and delivery in a flowing medium. Lab Chip 5(10):1059-1066.

Wang Z, Kim MC, Marquez M, Thorsen T (2007) High-density microfluidic arrays for cell cytotoxicity analysis. Lab Chip 7(6):740-745.

15 Zanzotto A, Szita N, Schmidt MA, Jensen KF (2002) $2^{\text {nd }}$ Annual International IEEE-EMBS Special Topic Conference on Microtechnologies in Medicine \& Biology 164-168, Madison, Wisconsin USA.

Zhang ZY, Boccazzi P, Choi HG et al (2006) Microchemostat - microbial continuous culture in a polymer-based, instrumented microbioreactor. Lab Chip 6(7):906-913.

Ziomek E, Kirkpatrick N, Reid ID (1991) Effect of poldimethyl siloxane oxygen carriers on the biological bleaching of hardwood kraft pulp by trametes-versicolor. Appl Microbiol Biotechnol 35(5):669-673.

web 1: http://www.engineeringtoolbox.com/oxygen-solubility-water-d_841.html

web 2: http://compost.css.cornell.edu/oxygen/oxygen.diff.water.html

\section{Figure Legends}

Figure 1. Schematic of the microchannel used for mass transport modeling, consisting of a gas channel, a PDMS membrane, a medium channel/chamber, a cell layer and an oxygen-impermeable glass substrate. 
Figure 2. Surface plot of $O P D$ as a function of variables $A$ and $B$; it is important to note that the $O P D$ becomes a linear function at the range of $B$ from 0 to 1 and $A$ approaching zero.

Figure 3. (a) Photograph and (b) cross-section schematic diagram of a device for $O P D$ validation. (c) HUVECs were cultured along microchannels with different $\rho^{*}$ cell to measure the corresponding $O P D$.

5 Figure 4. Comparison between the semi-analytical solution (AS) and the numerical solution (NS) during the development of (a) steady state $\mathrm{pO}_{2}$ profile $(t=70 \mathrm{~s})$ when there is gas transfer through the PDMS membrane and medium flow in the channel. (b) The $\mathrm{pO}_{2}$ along cell layer at different simulation time indicates reasonable agreement between the AS and the NS. Simulated (c) dimensionless $\left(g_{i}\right)$ and $(\mathbf{d})$ dimensional $\left(c_{i}\right)$ oxygen concentration along $y$ direction at $x=3 \mathrm{~mm}$ from

10 the channel entrance for $t=5 \mathrm{~s}, 10 \mathrm{~s}, 30 \mathrm{~s}$ and $70 \mathrm{~s}$.

Figure 5. Semi-analytical solution (AS) and experimental values (Exp) of rise time $\left(T_{r}\right)$ as a function of effective channel height $\left(H_{2}\right)$ and PDMS membrane thickness $\left(H_{3}\right)$. Each data point represents the mean value of at least three independent measurements. The error bars represent the standard deviation of each data point. It should be noted that some error bars are covered by the corresponding data points because the standard deviations are too small.

Figure 6. Plots of $P_{\text {cell }}^{*}$ verses $L^{*}$ under variations of (a) effective channel height $\left(H_{2}\right)$ and $(\mathbf{b})$ membrane thickness $\left(H_{3}\right)$ representing oxygen diffusion at cell layer $\left(K_{m}^{\prime}=0.5 \mathrm{mmHg}, V_{\max }=4 \times\right.$ $10^{-17} \mathrm{~mole} / \mathrm{cell} / \mathrm{s}$ and $\rho_{\text {cell }}^{*}=3 \times 10^{4}$ cells $/ \mathrm{cm}^{2}$ for HUVEC) along medium channel with the constant Peclet numbers $(P e=6$ in (a) and $P e=3$ in $(\mathbf{b}))$.

Figure 7. Variation in $O P D$ under two different configurations of (a) channel height and (b) PDMS thickness with two different cell types: $\operatorname{HUVEC}\left(K_{m}^{\prime}=0.5 \mathrm{mmHg}, V_{\max }=4 \times 10^{-17} \mathrm{~mole} / \mathrm{cell} / \mathrm{s}\right.$ and $\rho_{\text {cell }}^{*}=3 \times 10^{3}, 3 \times 10^{4}$ and $3 \times 10^{5}$ cells $\left./ \mathrm{cm}^{2}\right)$ and hepatocyte (Hepa) cells $\left(K_{m}^{\prime}=5.6 \mathrm{mmHg}, V_{\max }=\right.$ $3.8 \times 10^{-16} \mathrm{~mole} / \mathrm{cell} / \mathrm{s}$ and $\rho^{*}{ }_{\text {cell }}=3.16 \times 10^{3}$ and $3.16 \times 10^{4}$ cells $\left./ \mathrm{cm}^{2}\right)$. All calculated values show excellent agreement between theoretical solution (TS, see Eq (28)) and numerical solution (NS). Contour plots for these parametric studies (with $\rho_{\text {cell }}^{*}=3 \times 10^{4}$ cells $/ \mathrm{cm}^{2}$ of HUVEC) are available in Figure S1 \& S2 in Supplementary Material. 


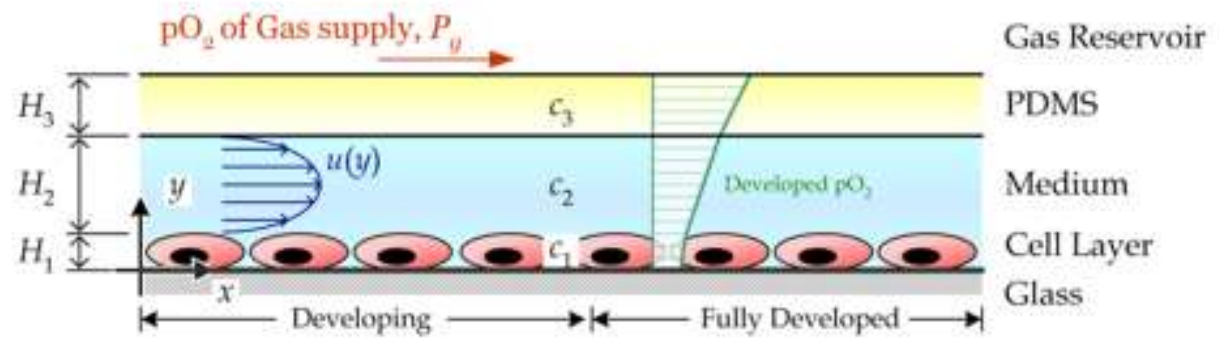

Figure 1

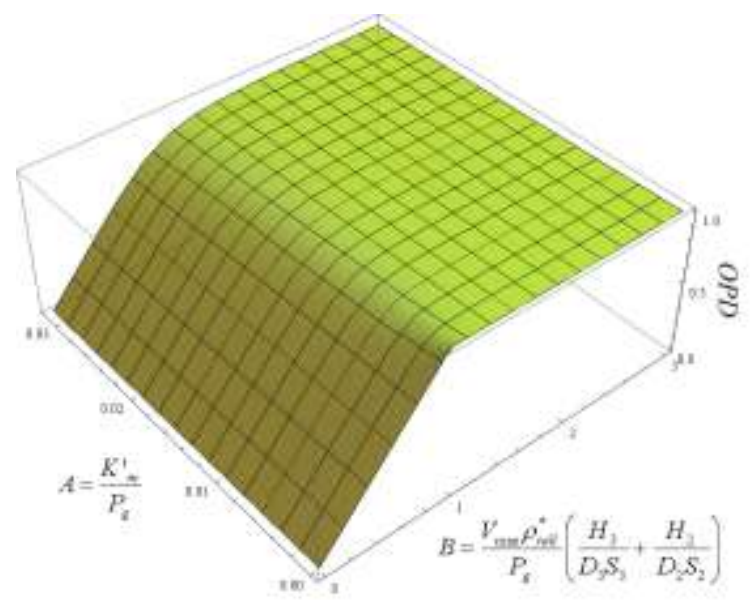

Figure 2

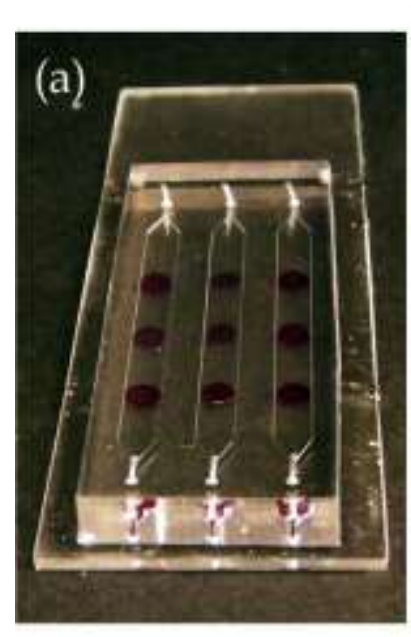

(b)
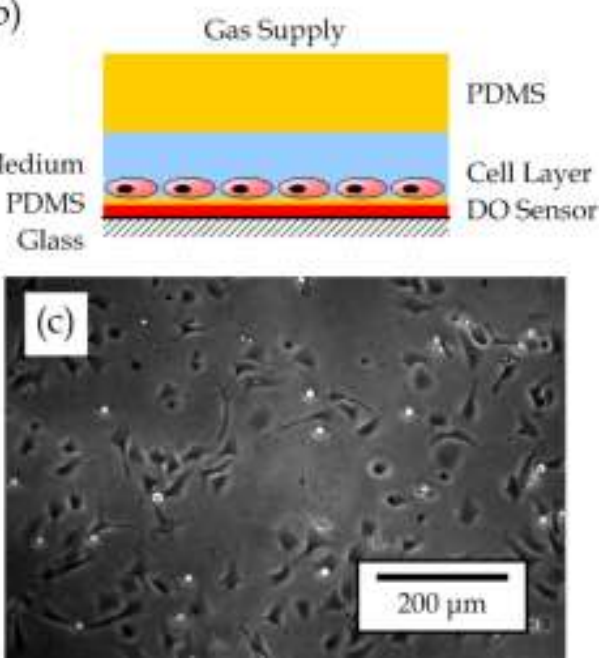

Figure 3 

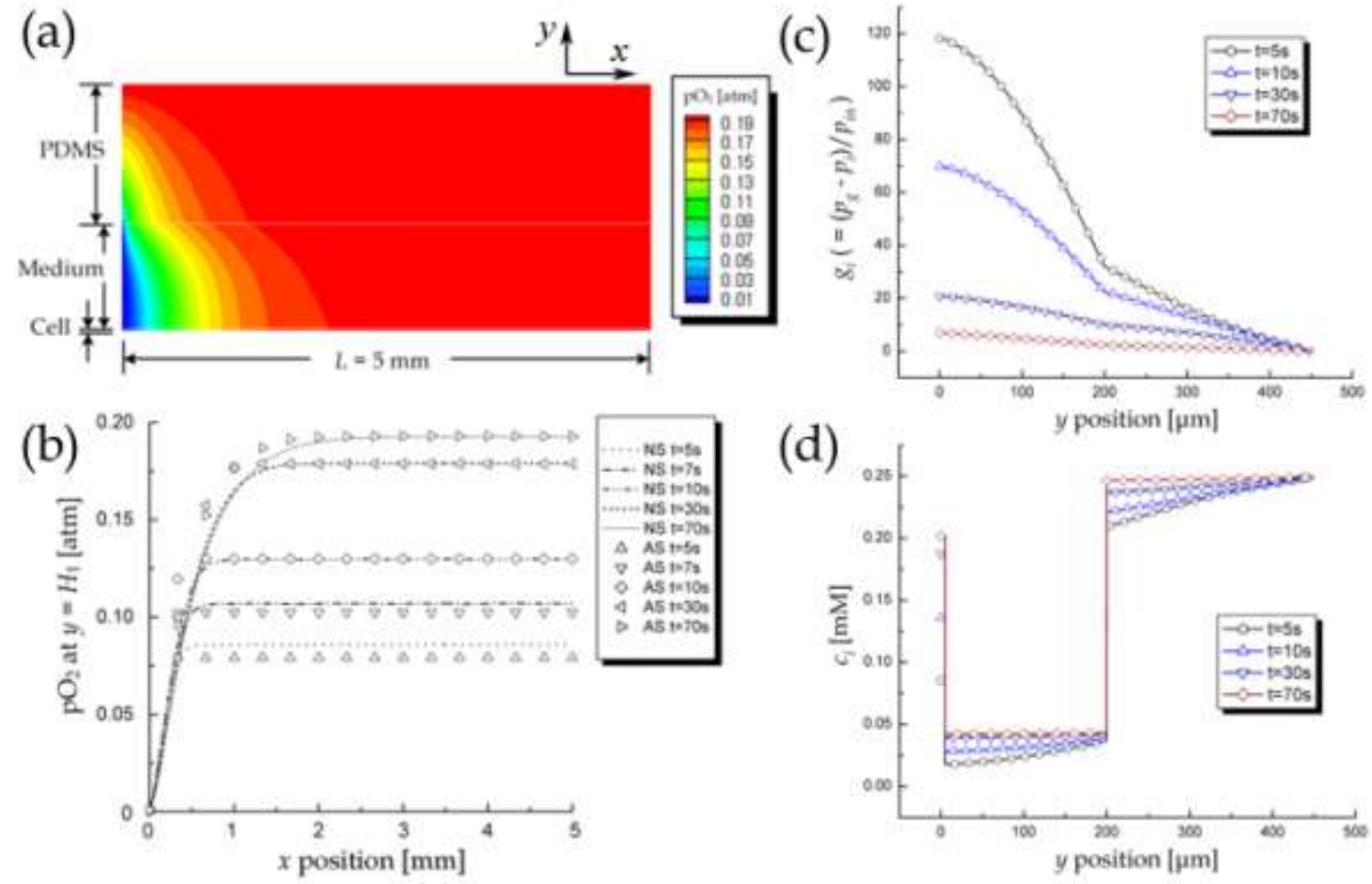

(d)

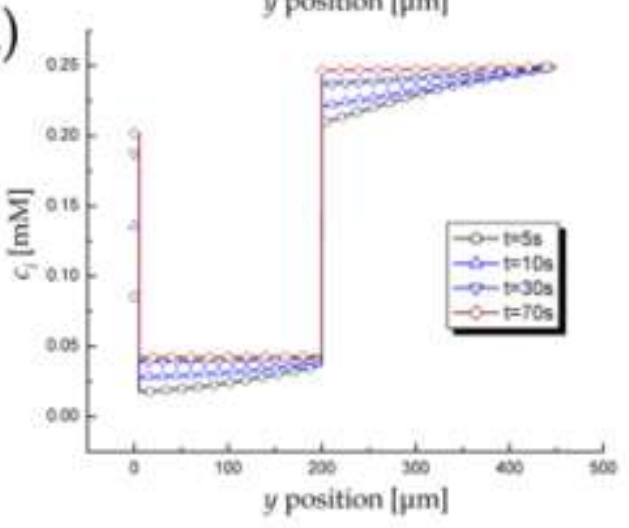

Figure 4

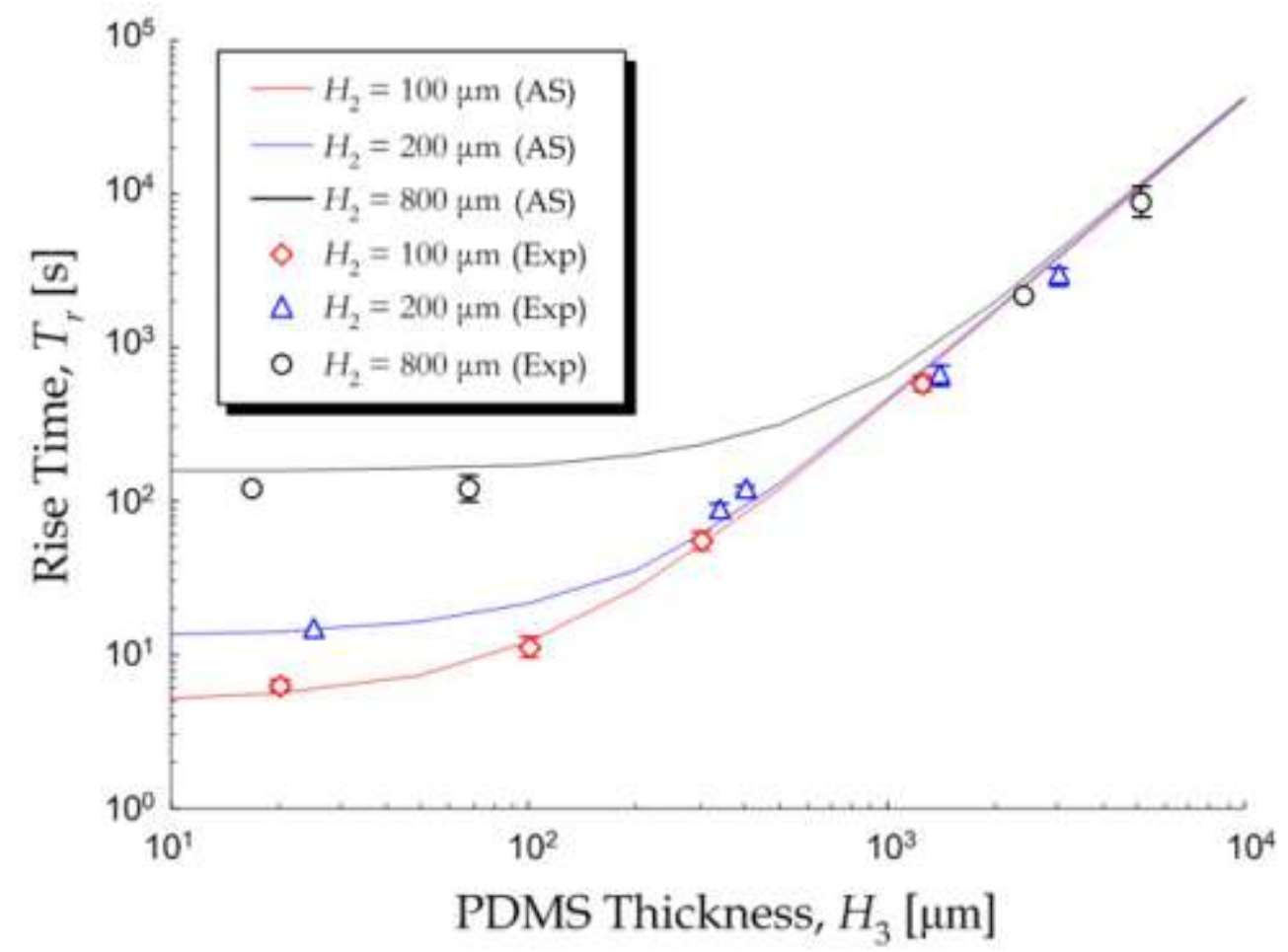

Figure 5 
(a)

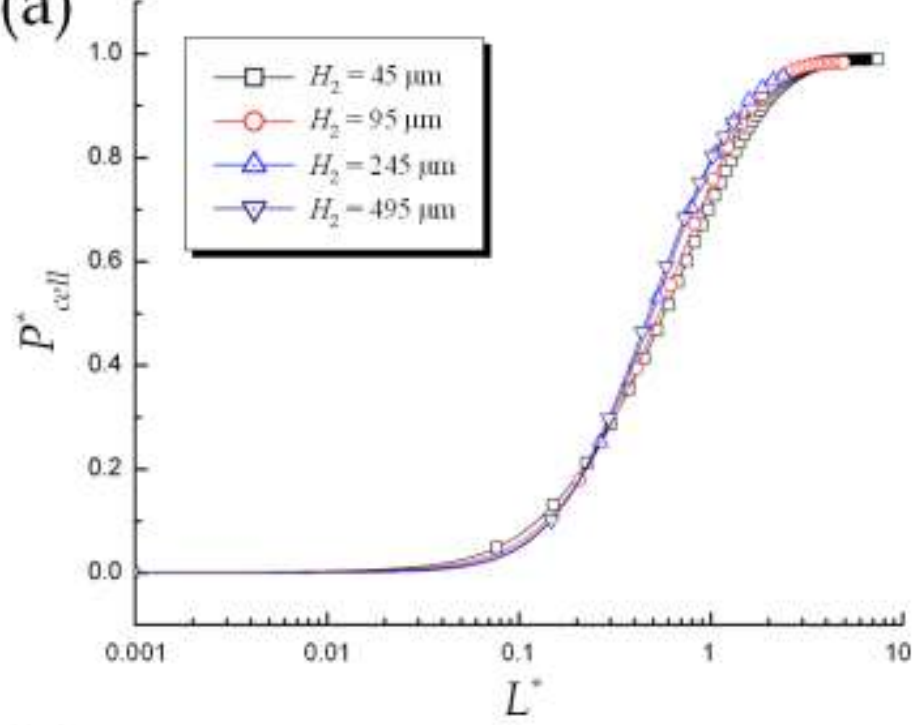

(b)

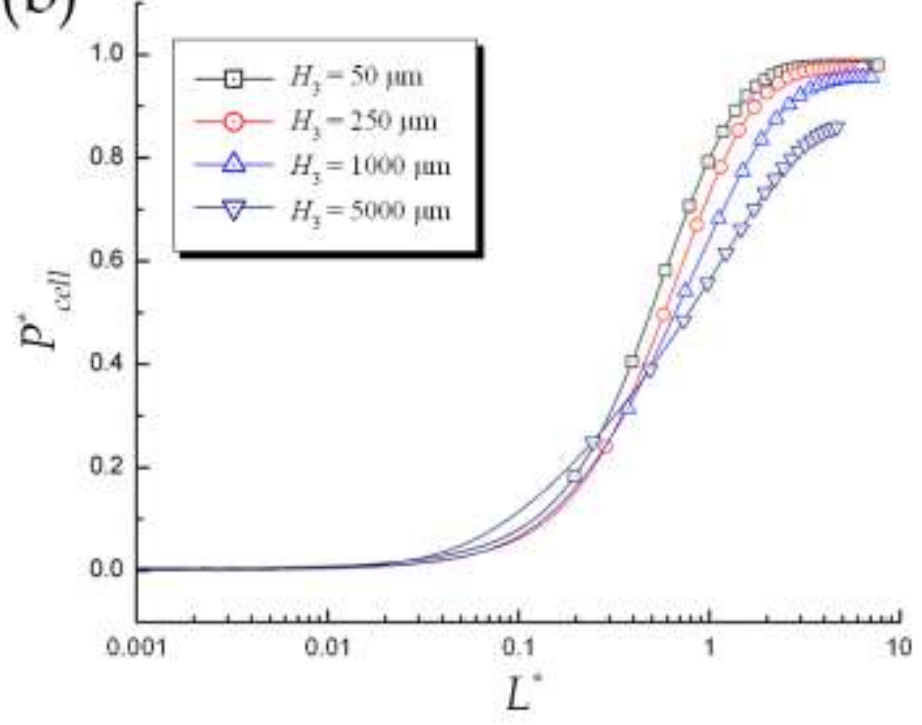

Figure 6 


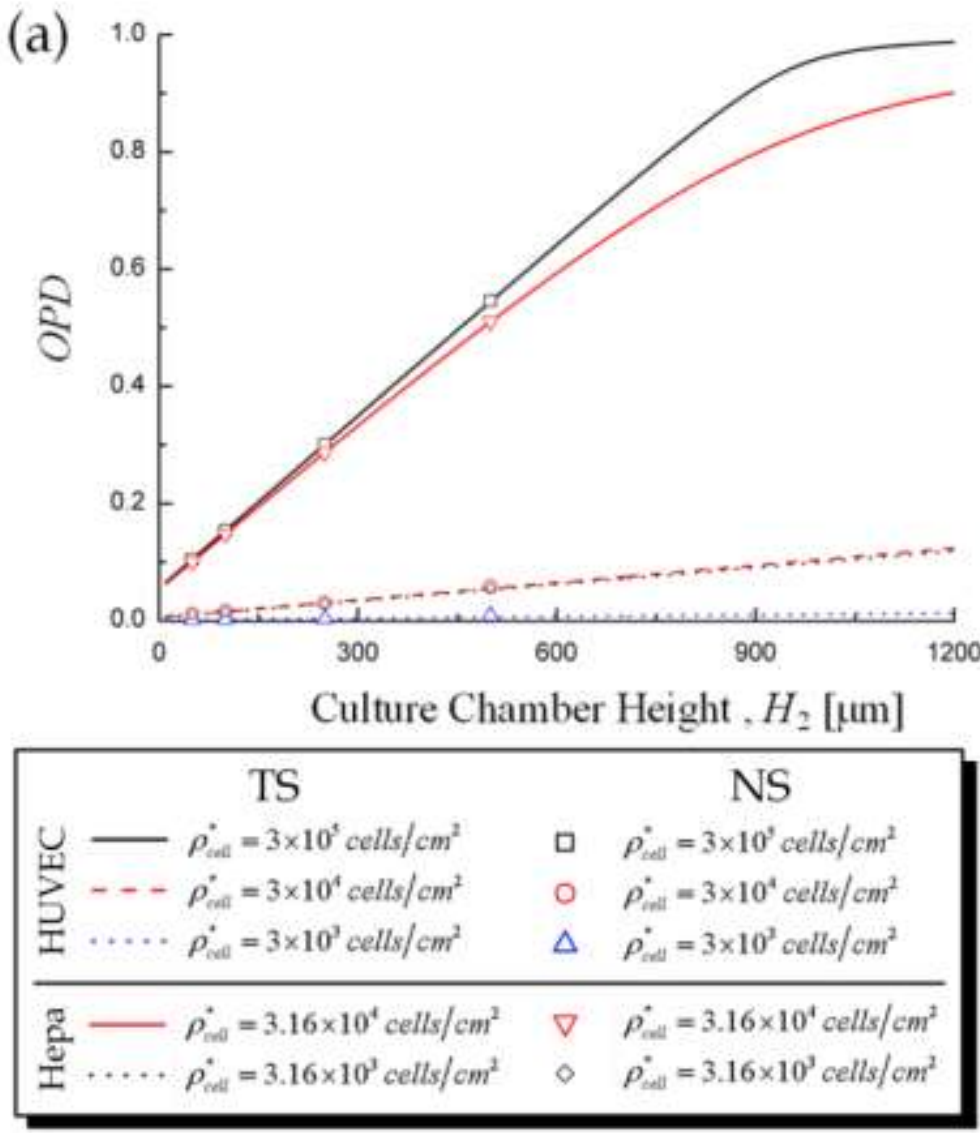

(b)

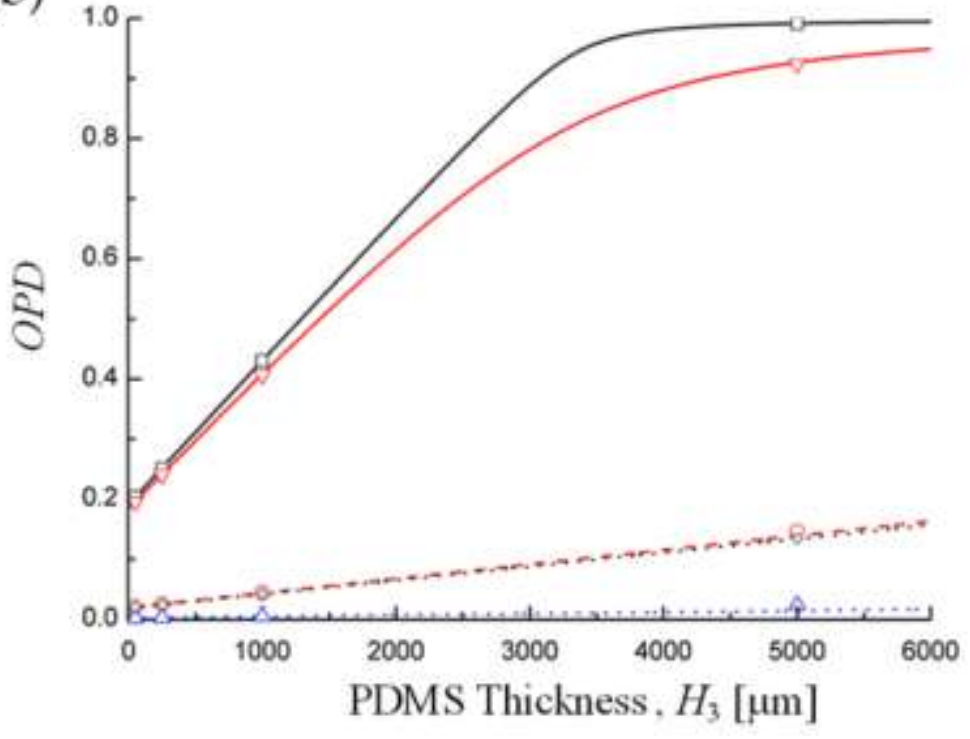

Figure 7 


\section{Tables}

Table 1: Diffusivity and Solubility of Cells, medium and PDMS

\begin{tabular}{lll}
\hline Material & Solubility $[\mathbf{m M / a t m}]$ & Diffusivity $\left[\mathbf{c m}^{2} / \mathbf{s}\right]$ \\
\hline Cell & 1.049 (chakraborty S et al. 2007) & $9.5 \times 10^{-6}$ \\
& & (chakraborty S et al. 2007) \\
Medium (water) & 0.218 at $37^{\circ} \mathrm{C}$ (web 1) & $2.8 \times 10^{-5}$ (web 2) \\
PDMS & 1.25 & $7.88 \times 10^{-5}$ \\
& (Valeur B and Brochon JC 2001; Shiku H et al. 2006) & (Ziomek E et al. 1991)
\end{tabular}

5

* The diffusivity of oxygen in PDMS can vary depending on temperature (Tan JL et al. 2003; Park J et al. 2006).

Table 2: Experimental measures of $O P D$ of HUVEC cultured in microchannels

\begin{tabular}{lcccc}
\hline \multicolumn{4}{c}{ Total Cell Coverage $\left[\times \mathbf{1 0}^{\mathbf{4}}\right.$ cells/cm $\left.\mathbf{c m}^{2}\right]$} \\
\cline { 2 - 5 } & $\mathbf{0 . 6 7} \pm \mathbf{0 . 0 5}(\mathbf{S D})$ & $\mathbf{1 . 5 4} \pm \mathbf{0 . 1 2}$ & $\mathbf{3 . 6 8} \pm \mathbf{0 . 2 1}$ & $\mathbf{4 . 0 4} \pm \mathbf{0 . 2 9}$ \\
\hline OPD & $0.021 \pm 0.009(\mathrm{SD})$ & $0.072 \pm 0.026$ & $0.157 \pm 0.030$ & $0.166 \pm 0.033$ \\
Equivalent $V_{\max }$ & 2.38 & 3.55 & 3.23 & 3.12 \\
{$\left[\times 10^{-17} \mathrm{~mole} / \mathrm{cell} / \mathrm{s}\right]$} & & & & \\
\hline
\end{tabular}

\section{Supplementary Material for}

10 Mathematical Analysis of Oxygen Transfer through Polydimethylsiloxane Membrane between Double Layers of Cell Culture Channel and Gas Chamber in Microfluidic Oxygenator

\footnotetext{
Min-Cheol Kim ${ }^{1,2,+, *}$, Raymond H. W. Lam ${ }^{1,3, \dagger}$, and Todd Thorsen ${ }^{1, *}$ H. Harry Asada ${ }^{1,2}$

${ }^{1}$ Department of Mechanical Engineering, Massachusetts Institute of Technology, Cambridge, MA 02139

$15{ }^{2}$ BioSystem \& Micromechanics IRG, Singapore MIT Alliance Research Technology, Singapore, 117543

${ }^{3}$ Department of Mechanical and Biomedical Engineering, City University of Hong Kong, Hong Kong, China
} 
$\uparrow$ Authors contributed equally to this work.

* To whom correspondence should be addressed: mincheol@ mit.edu; thorsen@mit.edu

Table of Contents

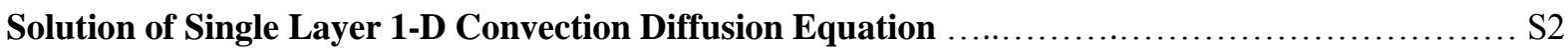

Semi-Analytical Solution of Multiple Layer Transient 2-D Convection Diffusion Equations......... S5

10 Derivation of the Dimensionless Oxygen Pressure Drop (OPD) ........................................... S6

Sample pO2 Profiles with Different Oxygenation Configurations.................................. S7

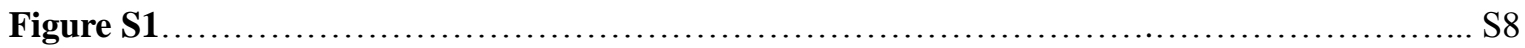

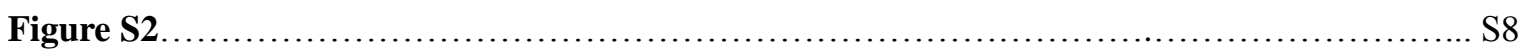

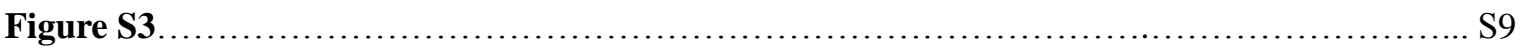

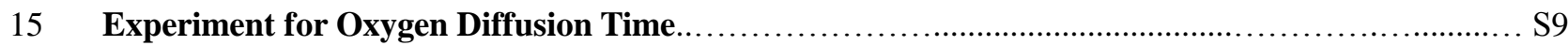

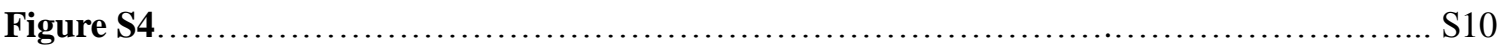

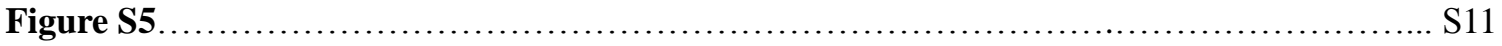

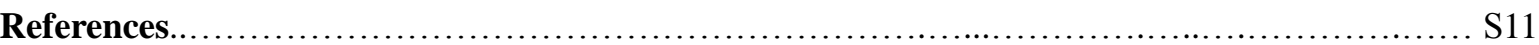




\section{Solution of Single Layer 1-D Convection Diffusion Equation}

The dimensionless 1-D convective diffusion equation and boundary conditions are expressed as

$$
\alpha_{i}^{2} \frac{\partial g_{i}}{\partial \tau}=\frac{\partial^{2} g_{i}}{\partial \psi^{2}}+m_{i} \text { for } \beta_{i-1} \leq \psi \leq \beta_{i} \text { and } 0 \leq \xi \leq 1
$$

$$
\begin{gathered}
-\left.\frac{\partial g_{i}}{\partial \psi}\right|_{\psi=\beta_{i-1}}=\operatorname{Sh}(\psi)\left(G_{i}(\zeta, \tau)-g(\zeta, \psi, \tau)\right) \\
-\left.\frac{\partial g_{i}}{\partial \psi}\right|_{\psi=\beta_{i}}=\operatorname{Sh}(\psi)\left(g(\zeta, \psi, \tau)-G_{i+1}(\zeta, \tau)\right)
\end{gathered}
$$

where $\operatorname{Sh}(\psi)\left(=\frac{h_{N} K(\psi)}{D_{i}}\right)$ is Sherwood number $(S h)$ representing the ratio of length scale to the diffusive boundary layer thickness $\left(h_{N}\right)$, and $K(\psi)$ is the film mass transfer coefficient at the boundary $\psi$. To solve this non-homogeneous boundary value problem, we may let

$$
g_{i}(\xi, \psi, \tau)=v_{i}(\xi, \psi, \tau)+\sum_{j=1}^{2} L_{i j}(\psi) F_{i j}(\xi, \tau) \text { for } \beta_{i-1} \leq \psi \leq \beta_{i} \text { and } 0 \leq \xi \leq 1, \tau>0
$$

where $\frac{d^{2} L_{i j}(\psi)}{d \psi^{2}}=0$ so that $L_{i j}(\psi)=C_{i j}^{1} \psi+C_{i j}^{2}$ for $\beta_{i-1} \leq \psi \leq \beta_{i}$ and $O \leq \xi \leq 1, i=1,2, \ldots, N, j=1,2$.

$F_{i 1}(\xi, \tau)=G_{i}(\xi, \tau)$ and $F_{i 2}(\xi, \tau)=G_{i+1}(\xi, \tau)$ are unknown variables at boundaries of the $i^{\text {th }}$ material.

Substituting these results into Eq. S1 gives

$$
\alpha_{i}^{2} \frac{\partial v_{i}}{\partial \tau}+\alpha_{i}^{2} \sum_{j=1}^{2} L_{i j}(\psi) \frac{\partial F_{i j}(\xi, \tau)}{\partial \tau}=\frac{\partial^{2} v_{i}}{\partial \psi^{2}}+m_{i}
$$

The boundary conditions described in Eqs. S2-S3 are decomposed as (39)

$$
\begin{aligned}
& D_{i} \frac{\partial v_{i}\left(\xi, \beta_{i-1}, \tau\right)}{\partial \psi}-h_{N} K\left(\beta_{i-1}\right) v\left(\xi, \beta_{i-1}, \tau\right)=0 \\
& D_{i} \frac{\partial v_{i}\left(\xi, \beta_{i}, \tau\right)}{\partial \psi}+h_{N} K\left(\beta_{i}\right) v\left(\xi, \beta_{i}, \tau\right)=0 \\
& D_{i} \frac{d L_{i 1}\left(\beta_{i-1}\right)}{d \psi}-h_{N} K\left(\beta_{i-1}\right) L_{i 1}\left(\beta_{i-1}\right)=-h_{N} K\left(\beta_{i-1}\right) \\
& D_{i} \frac{d L_{i 1}\left(\beta_{i}\right)}{d \psi}+h_{N} K\left(\beta_{i}\right) L_{i 1}\left(\beta_{i}\right)=0 \\
& D_{i} \frac{d L_{i 2}\left(\beta_{i-1}\right)}{d \psi}-h_{N} K\left(\beta_{i-1}\right) L_{i 2}\left(\beta_{i-1}\right)=0 \\
& D_{i} \frac{d L_{i 2}\left(\beta_{i}\right)}{d \psi}+h_{N} K\left(\beta_{i}\right) L_{i 2}\left(\beta_{i}\right)=h_{N} K\left(\beta_{i}\right)
\end{aligned}
$$

where Eqs. S8-S9 and S10-S11 are boundary conditions used to solve $L_{i 1}(\psi)$ and $L_{i 2}(\psi)$, respectively. Assuming $K\left(\beta_{i-1}\right), K\left(\beta_{i}\right) \rightarrow \infty$, the solutions of $L_{i 1}(\psi)$ and $L_{i 2}(\psi)$ are

$$
L_{i 1}(\psi)=\frac{\beta_{i}-\psi}{\beta_{i}-\beta_{i-1}}, L_{i 2}(\psi)=\frac{\psi-\beta_{i-1}}{\beta_{i}-\beta_{i-1}}
$$

with the initial condition 


$$
v_{i}\left(\xi, \psi, \tau_{0}\right)=g_{i}\left(\xi, \psi, \tau_{0}\right)-\sum_{j=1}^{2} L_{i j}(\psi) F_{i j}\left(\xi, \tau_{0}\right)=f_{i}(\xi, \psi)-\sum_{j=1}^{2} L_{i j}(\psi) F_{i j}\left(\xi, \tau_{0}\right)
$$

Now, we may let

$$
\begin{array}{cc}
v_{i}(\xi, \psi, \tau)=\sum_{n=1}^{\infty} V_{i, n}(\xi, \tau) \Psi_{i, n}(\psi) & \beta_{i-1} \leq \psi \leq \beta_{i}, 0 \leq \xi \leq 1, \tau \geq 0 \\
m_{i}(\xi, \psi, \tau)=\sum_{n=1}^{\infty} M_{i, n}(\xi, \tau) \Psi_{i, n}(\psi) & \beta_{i-1} \leq \psi \leq \beta_{i}, 0 \leq \xi \leq 1, \tau \geq 0
\end{array}
$$

$5 \quad$ where $M_{i, n}(\xi, \tau)=\frac{\int_{\beta_{i-1}}^{\beta_{i}} m_{i}(\xi, \psi, \tau) \Psi_{i, n}(\psi) d \psi}{\int_{\beta_{i-1}}^{\beta_{i}} \Psi_{i, n}(\psi)^{2} d \psi}$

Assume $L_{i j}(\psi)=\sum_{n=1}^{\infty} l_{i j, n} \Psi_{i, n}(\psi)$ for $\beta_{i-1} \leq \psi \leq \beta_{i}$, where $l_{i j, n}=\frac{\int_{\beta_{i-1}}^{\beta_{i}} L_{i j}(\psi) \Psi_{i, n}(\psi) d \psi}{\int_{\beta_{i-1}}^{\beta_{i}} \Psi_{i, n}(\psi)^{2} d \psi}$, and substituting Eqs. S14 and S15 into Eq. S5:

$$
\alpha_{i}^{2} V_{i, n}^{\prime}(\xi, \tau) \Psi_{i, n}(\psi)+\alpha_{i}^{2} \sum_{j=1}^{2} l_{i j, n} \frac{\partial F_{i j}(\xi, \tau)}{\partial \tau} \Psi_{i, n}(\psi)-M_{i, n}(\xi, \tau) \Psi_{i, n}(\psi)=\Psi_{i, n}{ }^{\prime \prime}(\psi) V_{i, n}(\xi, \tau)
$$

Dividing Eq. S16 by $\alpha_{i}^{2} V_{i, n}(\xi, \tau) \Psi_{i, n}(\psi)$ yields

$$
\frac{V_{i, n}{ }^{\prime}(\xi, \tau)+\sum_{j=1}^{2} l_{i j, n} \frac{\partial F_{i j}(\xi, \tau)}{\partial \tau}-\frac{M_{i, n}(\xi, \tau)}{\alpha_{i}^{2}}}{V_{i, n}(\xi, \tau)}=\frac{\Psi_{i, n}^{\prime \prime}(\psi)}{\alpha_{i}^{2} \Psi_{i, n}(\psi)}=-\lambda_{i, n}^{2}
$$

where a positive constant $\lambda_{i, n}^{2}$ is used to set the above equation to be negative, such that the corresponding two ordinary differential equations are

$$
\begin{gathered}
V_{i, n}^{\prime}(\xi, \tau)+\lambda_{i, n}^{2} V_{i, n}(\xi, \tau)=-\sum_{j=1}^{2} l_{i j, n} \frac{\partial F_{i j}(\xi, \tau)}{\partial \tau}+\frac{M_{i, n}(\xi, \tau)}{\alpha_{i}^{2}} \\
\Psi_{i, n}^{\prime \prime}(\psi)+\lambda_{i, n}^{2} \alpha_{i}^{2} \Psi_{i, n}(\psi)=0
\end{gathered}
$$

where the boundary conditions of eigenfunction in Eq. S19 are

$$
\begin{aligned}
& D_{i} \Psi_{i, n}^{\prime}\left(\beta_{i-1}\right)-h_{N} K\left(\beta_{i-1}\right) \Psi_{i, n}\left(\beta_{i-1}\right)=0 \\
& D_{i} \Psi_{i, n}^{\prime}\left(\beta_{i}\right)+h_{N} K\left(\beta_{i}\right) \Psi_{i, n}\left(\beta_{i}\right)=0 .
\end{aligned}
$$

Hence the solution of Eq. S19 is $\Psi_{i, n}(\psi)=A_{i, n} \operatorname{Cos}\left(\lambda_{i, n} \alpha_{i} \psi\right)+B_{i, n} \operatorname{Sin}\left(\lambda_{i, n} \alpha_{i} \psi\right)$. Substituting this solution into Eqs. $\mathrm{S} 20-\mathrm{S} 21$ gives a matrix form as

$$
\left(\begin{array}{cc}
-D_{i} \lambda_{i, n} \alpha_{i} \operatorname{Sin}\left(\lambda_{i, n} \alpha_{i} \beta_{i-1}\right)-h_{N} K\left(\beta_{i-1}\right) \operatorname{Cos}\left(\lambda_{i, n} \alpha_{i} \beta_{i-1}\right) & D_{i} \lambda_{i, n} \alpha_{i} \operatorname{Cos}\left(\lambda_{i, n} \alpha_{i} \beta_{i-1}\right)-h_{N} K\left(\beta_{i-1}\right) \operatorname{Sin}\left(\lambda_{i, n} \alpha_{i} \beta_{i-1}\right) \\
-D_{i} \lambda_{i, n} \alpha_{i} \operatorname{Sin}\left(\lambda_{i, n} \alpha_{i} \beta_{i}\right)+h_{N} K\left(\beta_{i}\right) \operatorname{Cos}\left(\lambda_{i, n} \alpha_{i} \beta_{i}\right) & D_{i} \lambda_{i, n} \alpha_{i} \operatorname{Cos}\left(\lambda_{i, n} \alpha_{i} \beta_{i}\right)+h_{N} K\left(\beta_{i}\right) \operatorname{Sin}\left(\lambda_{i, n} \alpha_{i} \beta_{i}\right)
\end{array}\right)\left(\begin{array}{l}
A_{i, n} \\
B_{i, n}
\end{array}\right)=\left(\begin{array}{l}
0 \\
0
\end{array}\right)(\operatorname{S}
$$

The orthogonality of the eigenstates, $\operatorname{Cos}\left(\lambda_{i, n} \alpha_{i} \psi\right)$ and $\operatorname{Sin}\left(\lambda_{i, n} \alpha_{i} \psi\right)$, lead to a condition for the eingenvalue spectrum: 
$\left|\begin{array}{cc}-D_{i} \lambda_{i, n} \alpha_{i} \operatorname{Sin}\left(\lambda_{i, n} \alpha_{i} \beta_{i-1}\right)-h_{N} K\left(\beta_{i-1}\right) \operatorname{Cos}\left(\lambda_{i, n} \alpha_{i} \beta_{i-1}\right) & D_{i} \lambda_{i, n} \alpha_{i} \operatorname{Cos}\left(\lambda_{i, n} \alpha_{i} \beta_{i-1}\right)-h_{N} K\left(\beta_{i-1}\right) \operatorname{Sin}\left(\lambda_{i, n} \alpha_{i} \beta_{i-1}\right) \\ -D_{i} \lambda_{i, n} \alpha_{i} \operatorname{Sin}\left(\lambda_{i, n} \alpha_{i} \beta_{i}\right)+h_{N} K\left(\beta_{i}\right) \operatorname{Cos}\left(\lambda_{i, n} \alpha_{i} \beta_{i}\right) & D_{i} \lambda_{i, n} \alpha_{i} \operatorname{Cos}\left(\lambda_{i, n} \alpha_{i} \beta_{i}\right)+h_{N} K\left(\beta_{i}\right) \operatorname{Sin}\left(\lambda_{i, n} \alpha_{i} \beta_{i}\right)\end{array}\right|=0$

However, as $K\left(h_{i}\right), K\left(h_{i+1}\right) \rightarrow \infty$, the corresponding eigenvalues are $\lambda_{i, n}=n^{2} \pi^{2} / \alpha_{i}^{2}\left(\beta_{i}-\beta_{i-1}\right)^{2}$. This

Sturm-Louisville problem has been solved by implementing separation of variables on the homogeneous BVP of Eqs. S7-S8. The General solution for Eq. S18 at a simulation time $\tau$ is integrated from initial time $\tau_{0}$ that yields an expression written as

$$
\begin{aligned}
V_{i, n}(\xi, \tau) & =V_{i, n}\left(\xi, \tau_{0}\right) \operatorname{Exp}\left[-\lambda_{i, n}^{2}\left(\tau-\tau_{0}\right)\right] \\
& -\sum_{j=1}^{2} l_{i j, n} \int_{\tau_{0}}^{\tau} \frac{\partial F_{i j}(\xi, \varsigma)}{\partial \varsigma} \operatorname{Exp}\left[-\lambda_{i, n}^{2}(\tau-\varsigma)\right] d \varsigma+\frac{1}{\alpha_{i}^{2}} \int_{\tau_{0}}^{\tau} M_{i, n}(\xi, \varsigma) \operatorname{Exp}\left[-\lambda_{i, n}^{2}(\tau-\varsigma)\right] d \varsigma
\end{aligned}
$$

where $V_{i, n}\left(\xi, \tau_{0}\right)$ can be calculated with the initial condition Eq. S13:

$$
V_{i, n}\left(\xi, \tau_{0}\right)=\frac{\int_{\beta_{i-1}}^{\beta_{i}}\left(f_{i}(\xi, \psi)-\sum_{j=1}^{2} L_{i j}(\psi) F_{i j}\left(\xi, \tau_{0}\right)\right) \Psi_{i, n}(\psi) d \psi}{\int_{\beta_{i-1}}^{\beta_{i}} \Psi_{i, n}(\psi)^{2} d \psi}=\frac{\int_{\beta_{i-1}}^{\beta_{i}} f_{i}(\xi, \psi) \Psi_{i, n}(\psi) d \psi}{\int_{\beta_{i-1}}^{\beta_{i}} \Psi_{i, n}(\psi)^{2} d \psi}-\sum_{j=1}^{2} l_{i j, n} F_{i j}\left(\xi, \tau_{0}\right)
$$

Define $\Phi_{i, n}\left(f_{i}(\psi)\right)=\frac{\int_{\beta_{i-1}}^{\beta_{i}} f(\psi) \Psi_{i, n}(\psi) d \psi}{\int_{\beta_{i-1}}^{\beta_{i}} \Psi_{i, n}(\psi)^{2} d \psi}$ in Eq. S25 and we obtain

10

$$
\begin{aligned}
V_{i, n}(\xi, \tau) & =\left(\Phi_{i, n}\left(f_{i}(\xi, \psi)\right)-\sum_{j=1}^{2} l_{i j, n} F_{i j}\left(\xi, \tau_{0}\right)\right) \operatorname{Exp}\left[-\lambda_{n}^{2}\left(\tau-\tau_{0}\right)\right] \\
& -\sum_{j=1}^{2} l_{i j, n} \int_{\tau_{0}}^{\tau} \frac{\partial F_{i j}(\xi, \varsigma)}{\partial \varsigma} \operatorname{Exp}\left[-\lambda_{i, n}^{2}(\tau-\varsigma)\right] d \varsigma+\frac{1}{\alpha_{i}^{2}} \int_{\tau_{0}}^{\tau} M_{i, n}(\xi, \varsigma) \operatorname{Exp}\left[-\lambda_{i, n}^{2}(\tau-\varsigma)\right] d \varsigma
\end{aligned}
$$

By assuming $\frac{\partial F_{i j}(\xi, \varsigma)}{\partial \varsigma} \approx a_{j}$ and $M_{i, n}(\xi, \varsigma) \approx M_{i, n}\left(\xi, \tau_{0}\right)$ for the convolution terms in the above equation, Eq. S26 becomes

$$
\begin{aligned}
V_{i, n}(\xi, \tau) & =\left(\Phi_{i, n}\left(f_{i}(\xi, \psi)\right)-\sum_{j=1}^{2} l_{i j, n} F_{i j}\left(\xi, \tau_{0}\right)\right) \operatorname{Exp}\left[-\lambda_{i, n}{ }^{2}\left(\tau-\tau_{0}\right)\right] \\
& +\frac{1}{\lambda_{i, n}{ }^{2}}\left(\frac{M_{i, n}\left(\xi, \tau_{0}\right)}{\alpha_{i}{ }^{2}}-\sum_{j=1}^{2} l_{i j, n} a_{j}\right)\left(1-\operatorname{Exp}\left[-\lambda_{i, n}{ }^{2}\left(\tau-\tau_{0}\right)\right]\right)
\end{aligned}
$$

where $a_{j}=\frac{F_{i j}(\xi, \tau)-F_{i j}\left(\xi, \tau_{0}\right)}{\tau-\tau_{0}}$. Updating $\tau_{1}=\tau_{0}+\Delta \tau$, where $\tau_{1}$ is the current simulation time and $\Delta \tau$ is the time step, into Eq. S27 gives

$$
\begin{aligned}
V_{i, n}\left(\xi, \tau_{1}\right) & =\left(\Phi_{i, n}\left(f_{i}(\xi, \psi)\right)-\sum_{j=1}^{2} l_{i j, n} F_{i j}\left(\xi, \tau_{0}\right)\right) \operatorname{Exp}\left[-\lambda_{i, n}{ }^{2} \Delta \tau\right] \\
& +\frac{1}{\lambda_{i, n}{ }^{2}}\left(\frac{M_{i, n}\left(\xi, \tau_{0}\right)}{\alpha_{i}{ }^{2}}-\sum_{j=1}^{2} l_{i j, n} \frac{F_{i j}\left(\xi, \tau_{1}\right)-F_{i j}\left(\xi, \tau_{0}\right)}{\Delta \tau}\right)\left(1-\operatorname{Exp}\left[-\lambda_{i, n}{ }^{2} \Delta \tau\right]\right)
\end{aligned}
$$

When $\frac{\partial F_{i j}(\xi, \varsigma)}{\partial \varsigma} \approx \frac{F_{i j}(\xi, \tau)-F_{i j}\left(\xi, \tau_{0}\right)}{\tau-\tau_{0}}$ and $M_{i, n}(\xi, \varsigma) \approx M_{i, n}\left(\xi, \tau_{0}\right)$, 


$$
\begin{aligned}
& g_{i}(\xi, \psi, \tau)=\sum_{n=1}^{\infty}\left[\begin{array}{l}
\left(\Phi_{i, n}\left(f_{i}(\xi, \psi)\right)-l_{i 1, n} G_{i}\left(\xi, \tau_{0}\right)-l_{i 2, n} G_{i+1}\left(\xi, \tau_{0}\right)\right) \operatorname{Exp}\left[-\lambda_{n}{ }^{2} \Delta \tau\right] \\
+\frac{1}{\lambda_{i, n}{ }^{2}}\left(\frac{M_{i, n}\left(\xi, \tau_{0}\right)}{\alpha_{i}{ }^{2}}-l_{i, n} \frac{G_{i}(\xi, \tau)-G_{i}\left(\xi, \tau_{0}\right)}{\Delta \tau}-l_{i 1, n} \frac{G_{i+1}(\xi, \tau)-G_{i+1}\left(\xi, \tau_{0}\right)}{\Delta \tau}\right)\left(1-\operatorname{Exp}\left[-\lambda_{i, n}{ }^{2} \Delta \tau\right]\right)
\end{array}\right] \Psi_{i, n}(\psi) \\
& +L_{i 1}(\psi) G_{i}(\xi, \tau)+L_{i 2}(\psi) G_{i+1}(\xi, \tau) .
\end{aligned}
$$

\section{Semi-Analytical Solution of Multiple Layer Transient 2-D Convection Diffusion Equations}

5

To impose the dimensionless mass flux boundary conditions Eqs. 18, 20 and 22, the spatial derivative of $g_{i}(\xi, \psi, \tau)$ should be calculated as

$$
\begin{aligned}
& \frac{\partial g_{i}(\xi, \psi, \tau)}{\partial \psi}=\sum_{n=1}^{\infty}\left[\begin{array}{l}
\left(\Phi_{i, n}\left(f_{i}(\xi, \psi)\right)-l_{i l, n} G_{i}\left(\xi, \tau_{0}\right)-l_{i 2, n} G_{i+1}\left(\xi, \tau_{0}\right)\right) \operatorname{Exp}\left[-\lambda_{i, n}{ }^{2} \Delta \tau\right] \\
+\frac{1}{\lambda_{i, n}{ }^{2}}\left(\frac{M_{i, n}\left(\xi, \tau_{0}\right)}{\alpha_{i}{ }^{2}}-l_{i l, n} \frac{G_{i}(\xi, \tau)-G_{i}\left(\xi, \tau_{0}\right)}{\Delta \tau}-l_{i l, n} \frac{G_{i+1}(\xi, \tau)-G_{i+1}\left(\xi, \tau_{0}\right)}{\Delta \tau}\right)\left(1-\operatorname{Exp}\left[-\lambda_{i, n}{ }^{2} \Delta \tau\right]\right)
\end{array}\right] \frac{d \Psi_{i, n}(\xi, \psi)}{d \psi} \\
& +\frac{d L_{i 1}(\xi, \psi)}{d \psi} G_{i}(\xi, \tau)+\frac{d L_{i 2}(\xi, \psi)}{d \psi} G_{i+1}(\xi, \tau)
\end{aligned}
$$

where $\tau_{0}$ and $\Delta \tau$ are the dimensionless priori time of iteration and time-step, respectively. Rearrange Eq. S30 as a linear combination of unknown variables and source term:

$$
\frac{\partial g_{i}(\xi, \psi, \tau)}{\partial \psi}=Q_{i}(\xi, \psi, \Delta \tau) G_{i}(\xi, \tau)+R_{i}(\xi, \psi, \Delta \tau) G_{i+1}(\xi, \tau)+P_{i}\left(\xi, \psi, \tau_{0}, \Delta \tau\right)
$$

Where $P_{i}\left(\xi, \psi, \tau_{0}, \Delta \tau\right)$ is the source term, $Q_{i}(\xi, \psi, \Delta \tau)$ and $R_{i}(\xi, \psi, \Delta \tau)$ are the coefficients of unknown variables, which are expressed as $\mathrm{S} 1$

$$
\begin{gathered}
P_{i}\left(\xi, \psi, \tau_{0}, \Delta \tau\right)=\sum_{n=1}^{\infty}\left[\begin{array}{l}
\left(\Phi_{i, n}\left(f_{i}(\xi, \psi)\right)-l_{i 1, n} G_{i}\left(\xi, \tau_{0}\right)-l_{i 2, n} G_{i+1}\left(\xi, \tau_{0}\right)\right) \operatorname{Exp}\left[-\lambda_{i, n}{ }^{2} \Delta \tau\right] \\
+\frac{1}{\lambda_{i, n}{ }^{2}}\left(\frac{M_{i, n}\left(\xi, \tau_{0}\right)}{\alpha_{i}{ }^{2}}+\frac{l_{i 1, n} G_{i}\left(\xi, \tau_{0}\right)+l_{i 2, n} G_{i+1}\left(\xi, \tau_{0}\right)}{\Delta \tau}\right)\left(1-\operatorname{Exp}\left[-\lambda_{i, n}{ }^{2} \Delta \tau\right]\right)
\end{array}\right] \frac{d \Psi_{i, n}(\xi, \psi)}{d \psi} \\
Q_{i}(\xi, \psi, \Delta \tau)=\frac{d L_{i 1}(\xi, \psi)}{d \psi}-\frac{l_{i 1, n}}{\Delta \tau} \sum_{n=1}^{\infty}\left[\frac{1}{\lambda_{i, n}{ }^{2}}\left(1-\operatorname{Exp}\left[-\lambda_{i, n}{ }^{2} \Delta \tau\right]\right)\right] \frac{d \Psi_{i, n}(\xi, \psi)}{d \psi} \\
R_{i}(\xi, \psi, \Delta \tau)=\frac{d L_{i 2}(\xi, \psi)}{d \psi}-\frac{l_{i 2, n}}{\Delta \tau} \sum_{n=1}^{\infty}\left[\frac{1}{\lambda_{i, n}{ }^{2}}\left(1-\operatorname{Exp}\left[-\lambda_{i, n}{ }^{2} \Delta \tau\right]\right)\right] \frac{d \Psi_{i, n}(\xi, \psi)}{d \psi} .
\end{gathered}
$$

Using the mass flux boundary conditions, Eqs. 18, 20, 22 and 23 can be converted into linear algebraic equations written as a matrix form:

20

$$
A(\xi)=\left(\begin{array}{cccc}
Q_{1}(\xi, 0, \Delta \tau) & R_{1}(\xi, 0, \Delta \tau) & 0 & 0 \\
\frac{\delta_{1}}{\alpha_{1}^{2}} Q_{1}\left(\xi, \beta_{1}, \Delta \tau\right) & \frac{\delta_{1}}{\alpha_{1}^{2}} R_{1}\left(\xi, \beta_{1}, \Delta \tau\right)-Q_{2}\left(\xi, \beta_{1}, \Delta \tau\right) & -R_{2}\left(\xi, \beta_{1}, \Delta \tau\right) & 0 \\
0 & \alpha_{3}^{2} \delta_{2} Q_{2}\left(\xi, \beta_{2}, \Delta \tau\right) & \alpha_{3}^{2} \delta_{2} R_{2}\left(\xi, \beta_{2}, \Delta \tau\right)-Q_{3}\left(\xi, \beta_{2}, \Delta \tau\right) & -R_{3}\left(\xi, \beta_{2}, \Delta \tau\right) \\
0 & 0 & 0 & 1
\end{array}\right)
$$




$$
b(\xi)=\left(\begin{array}{c}
-P_{1}\left(\xi, 0, \tau_{0}, \Delta \tau\right) \\
-\frac{\delta_{1}}{\alpha_{1}^{2}} P_{1}\left(\xi, \beta_{1}, \tau_{0}, \Delta \tau\right)+P_{2}\left(\xi, \beta_{1}, \tau_{0}, \Delta \tau\right) \\
-\alpha_{3}^{2} \delta_{2} P_{2}\left(\xi, \beta_{2}, \tau_{0}, \Delta \tau\right)+P_{3}\left(\xi, \beta_{2}, \tau_{0}, \Delta \tau\right) \\
0
\end{array}\right) \text { and } X(\xi)=\left(\begin{array}{c}
G_{1}(\xi, \tau) \\
G_{2}(\xi, \tau) \\
G_{3}(\xi, \tau) \\
G_{4}(\xi, \tau)
\end{array}\right)
$$

These linear equations $A(\xi) \cdot X(\xi)=b(\xi)$ are readily solved line-by-line along to the channel axial direction $(0 \leq \xi$ $\leq 1)$ using tridiagonal matrix algorithm (TDMA $)^{S 2}$.

\section{Derivation of the Dimensionless Oxygen Pressure Drop (OPD)}

When the mass fluxes of oxygen across each material layer are identical, it can be expressed as

$$
q=\frac{D_{3} S_{3}}{H_{3}}\left(P_{g}-P_{2-3}\right)=\frac{2 D_{2} S_{2}}{H_{2}}\left(P_{2-3}-P_{2 b}\right)=\frac{2 D_{2} S_{2}}{H_{2}}\left(P_{2 b}-P_{\text {cell }}\right)
$$

where $P_{2-3}$ is the $\mathrm{pO}_{2}$ at the interface between PDMS membrane and medium channel, $P_{2 b}$ is the

bulk $\mathrm{pO}_{2}$ in medium, and $P_{\text {cell }}$ is the $\mathrm{pO}_{2}$ along top cell surface. If we correlate $q$ with the cellular oxygen uptake rate at the equilibrium state, $q$ can be written as

$$
q=\left.D_{1} \frac{\partial c_{1}}{\partial y}\right|_{y=H_{\text {cell }}}=\int_{0}^{H_{1}} \frac{V_{\max } \rho_{\text {cell }} c_{1}}{K_{m}+c_{1}} d y \approx \frac{V_{\max } \rho_{\text {cell }} c_{1}}{\mathrm{~S}_{1} K_{m}^{\prime}+c_{1}} H_{1}=\frac{V_{\max } \rho_{\text {cell }}^{*} P_{\text {cell }}}{K_{m}^{\prime}+P_{\text {cell }}}
$$

where $\rho_{\text {cell }}^{*}\left(=\rho_{\text {cell }} H_{l}\right)$ is the cell density [cells $/ \mathrm{cm}^{2}$ ]. Equation (S36) can be converted by following equation:

$$
q=\frac{\left(P_{g}-P_{2-3}\right)+\left(P_{2-3}-P_{2 b}\right)+\left(P_{2 b}-P_{\text {cell }}\right)}{\frac{H_{3}}{D_{3} S_{3}}+\frac{H_{2}}{D_{2} S_{2}}} .
$$

With equations (S37) and (S38), a quadratic equation with a variable $P_{\text {cell }}$ can be expressed as

$$
P_{\text {cell }}{ }^{2}+\left[\left(\frac{H_{3}}{D_{3} S_{3}}+\frac{H_{2}}{D_{2} S_{2}}\right) V_{\max } \rho_{\text {cell }}^{*}+K_{m}^{\prime}-P_{g}\right] P_{\text {cell }}-P_{g} K_{m}^{\prime}=0 .
$$

By dividing each term by $P_{g}^{2}$, equation (S39) yields

$$
\left(\frac{P_{\text {cell }}}{P_{g}}\right)^{2}-\left[1-\left(\frac{H_{3}}{D_{3} S_{3}}+\frac{H_{2}}{D_{2} S_{2}}\right) \frac{V_{\max } \rho_{\text {cell }}^{*}}{P_{g}}-\frac{K_{m}^{\prime}}{P_{g}}\right] \frac{P_{\text {cell }}}{P_{g}}-\frac{K_{m}^{\prime}}{P_{g}}=0 .
$$

20 To further simplify the equation (S40), we define $A=\frac{K_{m}^{\prime}}{P_{g}}$ and $B=\frac{V_{\max } \rho_{\text {cell }}^{*}}{P_{g}}\left(\frac{H_{3}}{D_{3} S_{3}}+\frac{H_{2}}{D_{2} S_{2}}\right)$, and it is simplified in following form:

$$
\left(\frac{P_{\text {cell }}}{P_{g}}\right)^{2}-(1-A-B) \frac{P_{\text {cell }}}{P_{g}}-A=0 .
$$

Solving for $\frac{P_{\text {cell }}}{P_{g}}$ gives 


$$
\frac{P_{\text {cell }}}{P_{g}}=\frac{(1-A-B) \pm \sqrt{(1-A-B)^{2}+4 A}}{2} .
$$

We define the dimensionless oxygen pressure drop (OPD) between the top cell surface and gas reservoir as

$$
O P D=\frac{P_{g}-P_{\text {cell }}}{P_{g}},
$$

and its exact solution can be simplified in following form:

$$
O P D=\frac{P_{g}-P_{\text {cell }}}{P_{g}}=\frac{1}{2}(1+A+B)-\frac{1}{2} \sqrt{(1-A-B)^{2}+4 A} .
$$

\section{Sample $\mathrm{pO}_{2}$ Profiles with Different Oxygenation Configurations}

10 Fig. S1(a-d) shows contour plots of the partial $\mathrm{pO}_{2}$ for four cases with different PDMS membrane thicknesses $\left(H_{3}\right) 50 \mu \mathrm{m}, 250 \mu \mathrm{m}, 1000 \mu \mathrm{m}$ and $6000 \mu \mathrm{m}$, respectively, at the steady state. For the qualitative comparison, the cell layer thickness $\left(H_{1}=5 \mu \mathrm{m}\right)$, effective channel height $\left(H_{2}=195 \mu \mathrm{m}\right)$, medium flow rate $(P e=3)$, cellular oxygen uptake rate $\left(V_{\max }=4 \times 10^{-17} \mathrm{~mole} / \mathrm{cell} / \mathrm{s}\right)$, surface cell coverage $\left(\rho^{*}\right.$ cell $\left.=3 \times 10^{4} \mathrm{cells} / \mathrm{cm}^{2}\right)$ and Michaelis-Menten constant $\left(K_{m}^{\prime}=0.5 \mathrm{mmHg}\right)$ were set to be identical for the four different PDMS membrane cases. The plots show that the developing length of $\mathrm{pO}_{2}$ (the length where medium starts being fully diffused, or $x$ for $L^{*} \sim 1$ ) increases with the membrane thickness, which is related to the diffusive resistance.

Another parametric study was conducted to investigate how the developing length relates to the effective channel height under the same Peclet number $(P e=6)$ and same surface cell coverage $\left(\rho_{\text {cell }}^{*}=3 \times 10^{4}\right.$ cells $\left./ \mathrm{cm}^{2}\right)$. Fig. S2(a-d) shows contour plots of the partial $\mathrm{pO}_{2}$ in four different effective channel heights $\left(\mathrm{H}_{2}\right) 50 \mu \mathrm{m}, 100$ $\mu \mathrm{m}, 250 \mu \mathrm{m}$ and $500 \mu \mathrm{m}$, respectively, at the steady state with fixed cell layer thickness $\left(H_{1}=5 \mu \mathrm{m}\right)$ and PDMS thickness $\left(H_{3}=250 \mu \mathrm{m}\right)$. All other parameters were the same as Fig. S1. The height of medium channel has similar effects on the diffusion time and developing length as the PDMS thickness.

Furthermore, Fig. S3(a-e) shows contour plots of the partial $\mathrm{pO}_{2}$ in five different cell layer thickness $\left(H_{1}\right)$ $10 \mu \mathrm{m}, 20 \mu \mathrm{m}, 50 \mu \mathrm{m}, 100 \mu \mathrm{m}$ and $150 \mu \mathrm{m}$, respectively, under steady state conditions with a fixed channel height $\left(H_{c}=200 \mu \mathrm{m}\right)$ and PDMS thickness $\left(H_{3}=250 \mu \mathrm{m}\right)$, and with all other parameters identical to the PDMS thickness study illustrated in Fig. S1. The developing length of $\mathrm{pO}_{2}$ gradually decreases as the cell layer grows in a limited culture channel (constant height: $H_{\mathrm{c}}=H_{1}+H_{2}$ ), inducing an increasing volumetric ratio of cell layer to medium, because the diffusive resistance of HUVEC $\left(H_{1} / S_{1} D_{1}\right)$ is smaller than that of culture medium $\left(H_{2} / S_{2} D_{2}\right)$. 


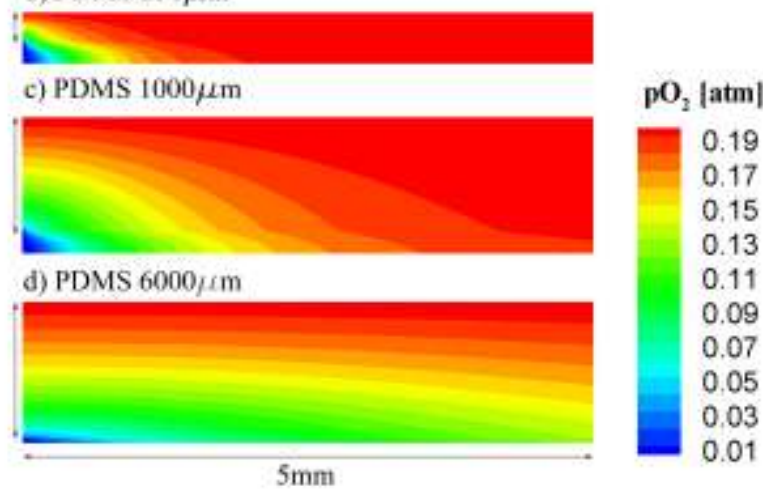

Figure S1: Contour plots of partial $\mathrm{pO}_{2}$ in a cross section of microfluidic device with $H_{1}$ of $5 \mu \mathrm{m}, H_{2}$ of 195 $\mu \mathrm{m}$, and four values of $H_{3}$, i.e. (a) $50 \mu \mathrm{m}$, (b) $250 \mu \mathrm{m}$, (c) $1000 \mu \mathrm{m}$ and (d) $6000 \mu \mathrm{m}$. Each case was simulated under identical conditions with the dimensionless parameters $P e=3, D a=3.93$.

\section{a) channel $50 \mu \mathrm{m}$}

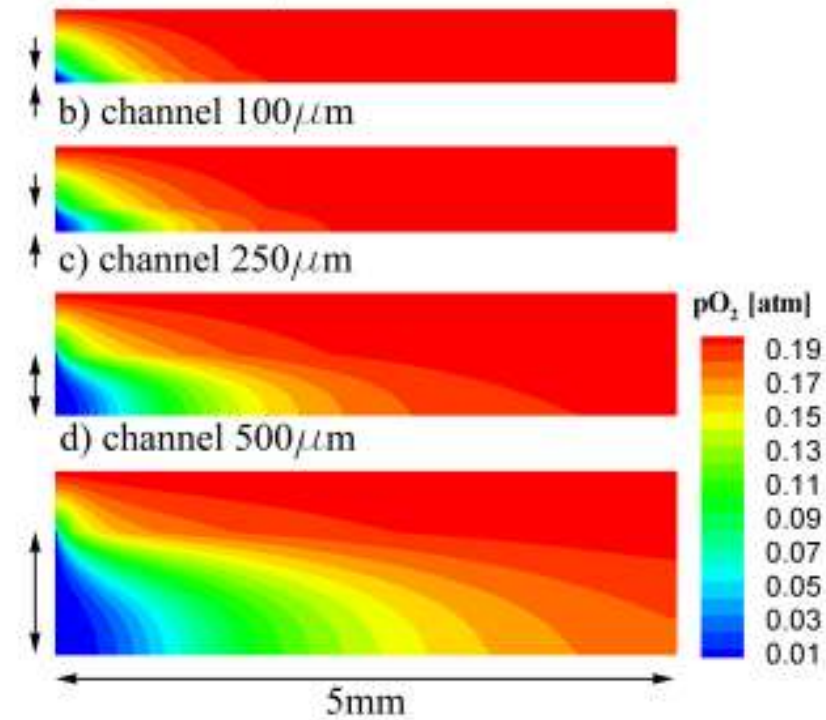

Figure S2: Contour plots of the partial $\mathrm{pO}_{2}$ in the microfluidic devices with $H_{1}=5 \mu \mathrm{m}, H_{3}=250 \mu \mathrm{m}$, and four different $H_{2}$ : (a) $50 \mu \mathrm{m}$, (b) $100 \mu \mathrm{m}$, (c) $250 \mu \mathrm{m}$ and (d) $500 \mu \mathrm{m}$. Each case was simulated under identical conditions with the dimensionless parameters $P e=6$ and $D a=0.98,1.96,4.91$ and 9.83 for (a) - (d), respectively. 


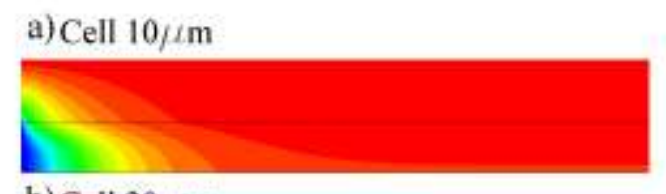

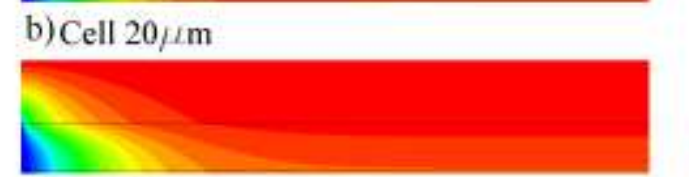

c) Cell $50 / \mathrm{m}$

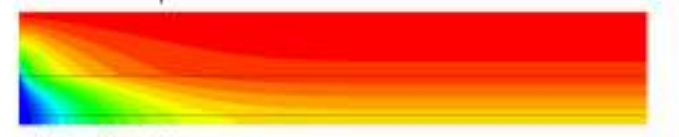

d)Cell $100 \mu \mathrm{m}$

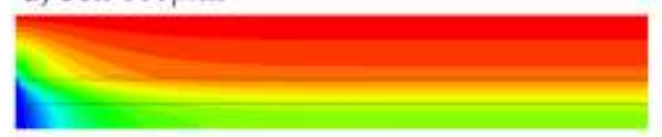

e) Cell $150 \mu \mathrm{m}$

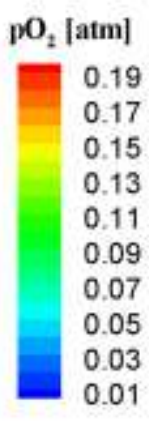

0.17

0.15

0.13

0.11

0.03

0.01

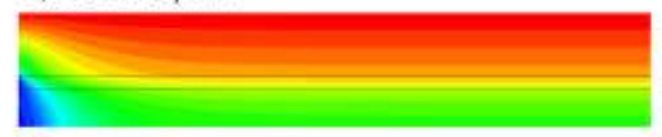

Figure S3: Contour plots of the partial $\mathrm{pO}_{2}$ in the microfluidic devices with $H_{c}=200 \mu \mathrm{m}, H_{3}=250 \mu \mathrm{m}$, and five different $H_{1}$ : (a) $10 \mu \mathrm{m}$, (b) $20 \mu \mathrm{m}$, (c) $50 \mu \mathrm{m}$, (d) $100 \mu \mathrm{m}$ and (e) $150 \mu \mathrm{m}$. Each case was simulated under identical conditions with the dimensionless parameters $P e=6$ and $D a=7.86,15.73,39.32,78.64$ and 117.96 for (a) - (e), respectively.

\section{Experiment for Oxygen Diffusion Time}

\section{Chip fabrication}

10 Experiments were performed to validate the simulated dissolved-oxygen (DO) concentration inside an elastomeric PDMS channel. Microfluidic chips containing arrays of double-layer structures (as described in the Diffusion Time of Oxygen Transfer section) with different layer thicknesses were fabricated by multilayer soft lithography ${ }^{\mathrm{S} 3}$ as shown in Fig. S4. Geometry of air and fluid channels was defined by SU-8/silicon molds, in which SU-8 negative photoresist (Microchem SU-8 50) was patterned on a silicon wafer. After cleaning a 3" silicon wafer (James River Semiconductors), SU-8 (thickness: $100 \mu \mathrm{m}$ ) was spin-coated (1000 rpm, $30 \mathrm{~s}$ ) on the wafer and patterned by photolithography (Karl Suss Mask Aligner MJB3, 2 min exposure). Afterwards the mold was silanized with a high molecular weight trichloro-perfluorooctyl silane (Aldrich) for $>5$ min to reduce the adhesion between polydimethylsiloxane (PDMS) and the Si/SU-8 surface. A mixture of 10:1 PDMS monomer/harder (Sylgard 184, Dow Corning) was prepared and poured onto the mold with the gas channel pattern before baking at $80{ }^{\circ} \mathrm{C}$ for $2 \mathrm{hr}$. Another 10:1 PDMS monomer/harder mixture was spin-coated (for $H_{2}+$ $H_{3} \leq 1000 \mu \mathrm{m}$ ) or poured (for $H_{2}+H_{3}>1000 \mu \mathrm{m}$ ) on the flow channel mold with the defined thickness $(100 \mu \mathrm{m})$ and was then baked in an oven at $80{ }^{\circ} \mathrm{C}$ for $10 \mathrm{~min}$. Taken out the gas layer mold from the oven, the PDMS substrate was cut and peeled off from the mold. After punching holes for the gas inlets and outlets, the gas layer was aligned onto the mold with the PDMS medium layer under a dissecting scope (Olympus, Model SZX9). To achieve permanent bonding and fully-cured PDMS, the whole PDMS substrate was post-baked in an oven at 80 ${ }^{\circ} \mathrm{C}$ for $>10 \mathrm{hr}$. The bonded PDMS was then chopped, peeled off and punched for medium inlets and outlets. On the other hand, a glass substrate containing DO sensors was prepared from a glass slide $(75 \mathrm{~mm}(\mathrm{l}) \times 25 \mathrm{~mm}(\mathrm{w})$ $\times 1 \mathrm{~mm}(\mathrm{~h})$ ). Each sensor region on the glass slide was etched with buffered hydrofluoric acid $\left(7 \mathrm{H}_{2} \mathrm{O}: 1 \mathrm{HF}\right)$ for 
5 min to produce a cavity $(\sim 5 \mu \mathrm{m})$. A polymeric sensor film was then deposited in each cavity by applying a droplet $(\sim 1 \mu \mathrm{L})$ of PtOEPK/polystyrene dye solution, prepared by first dissolving PtOEPK (Frontier Scientific, w/w $0.1 \%$ ) and polystyrene (w/w $5 \%$ ) into toluene. After toluene in the dye solution evaporates, oxygen-permeable PtOEPK/polystyrene films (thickness: $\sim 3 \mu \mathrm{m}$ ) were formed as DO sensors. The PDMS and glass substrates were then bonded by oxygen-plasma bonding process (PLASMOD, Tegal Corporation) with 600 mTorr pressure and medium power for $45 \mathrm{~s}$.
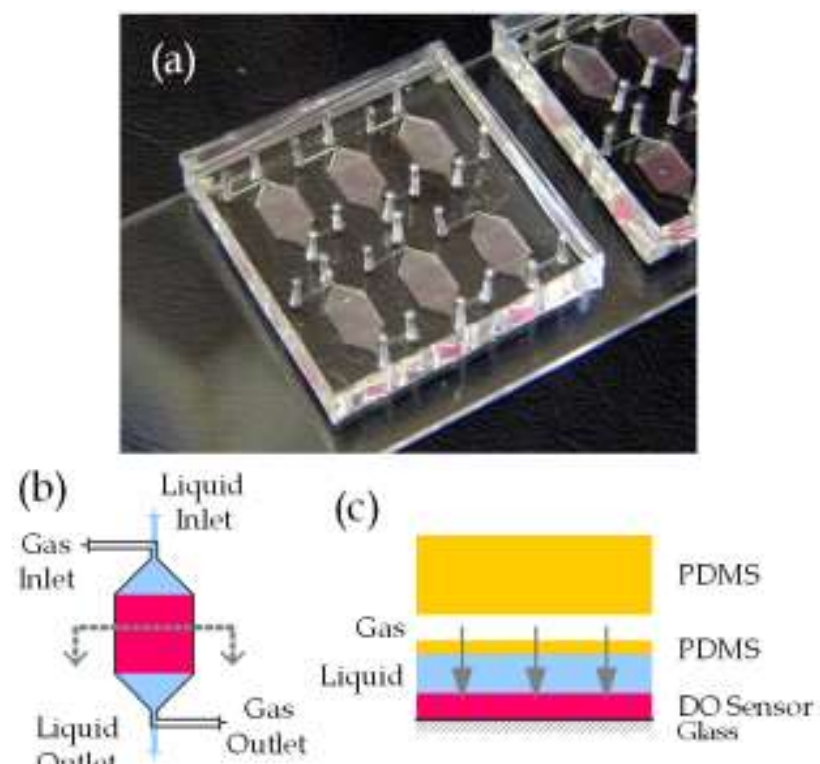

Figure S4: (a) Photograph and schematic diagrams of (b) top view and (c) cross-section of a PDMS chip for validation of diffusion time.

\section{Experimental procedures and sample results}

To measure the time-varying DO profile at the sensor layer, oxygen was continuously supplied along gas layer. Real-time measurement was achieved by a detection method based on the Stern-Volmer relation of PtOEPK that the reduction in luminescent intensity of sensing material due to oxygen quenching of the emitting excited electronic state ${ }^{\mathrm{S} 4} \mathrm{S5}$. In the experiment, the medium channel was initially filled with fresh medium under ambient environmental partial pressure and oxygen was then applied along the gas channel. The corresponding numerical oxygen profiles were also calculated using the approach described in section 4-2. Comparisons of the computational and experimental dynamic sensor responses indicate that the devices had similar $\mathrm{pO}_{2}$ profiles (Fig. S5) and response/rise time as numerical solution. 

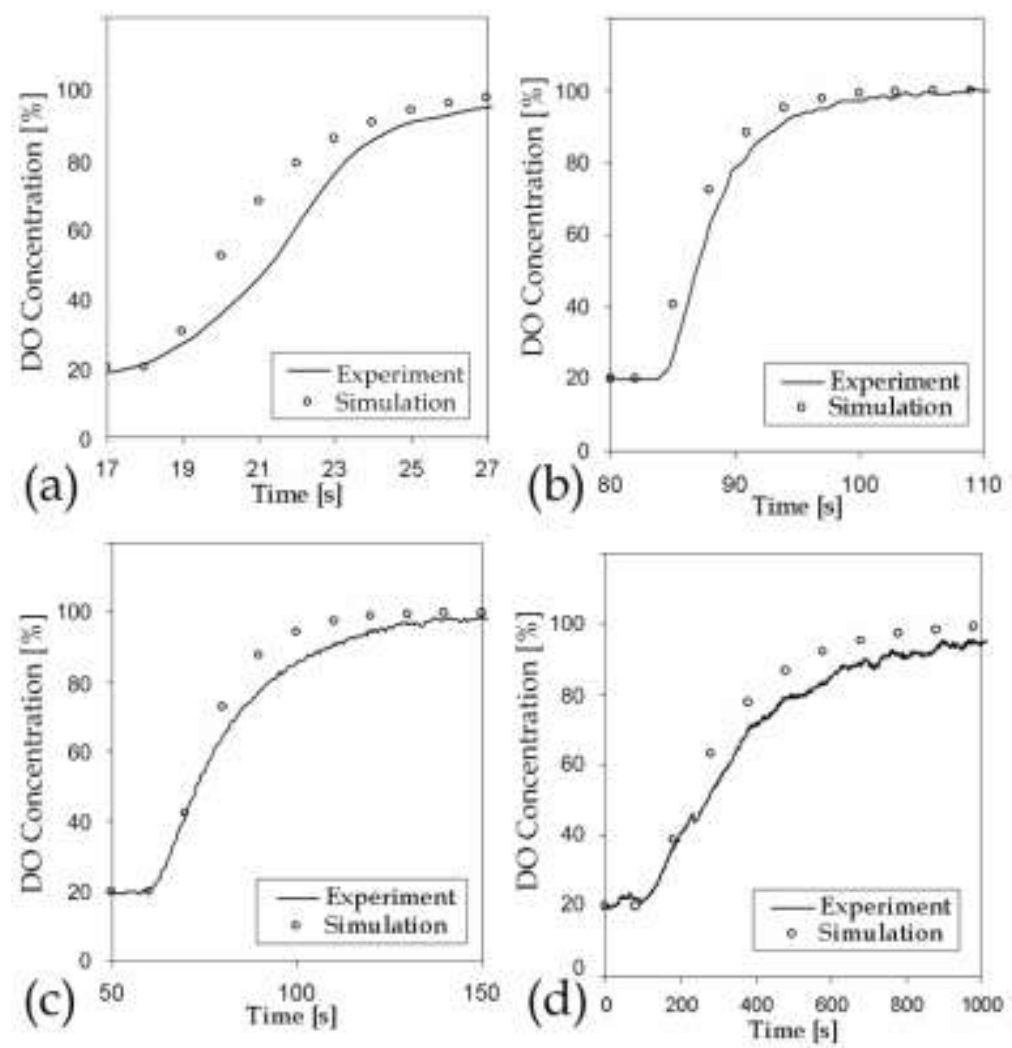

Figure S5: Sample sensor responses in the validation experiment of diffusion time and the corresponding simulation results for sensor thickness $\left(H_{1}\right) 3 \mu \mathrm{m}$, effective medium channel height $\left(H_{2}\right) \sim 100 \mu \mathrm{m}$ and membrane thickness $\left(H_{3}\right)(a) 20 \mu \mathrm{m}$, (b) $100 \mu \mathrm{m}$, (c) $300 \mu \mathrm{m}$, and (d) $1250 \mu \mathrm{m}$. The $y$ axes were normalized by scaling the fully saturated DO as value 1 .

\section{References}

S1 G. P. Mulholland and M. H. Cobble, Int. J. Heat Mass Transfer., 1972, 15, 147-160.

10 S2 T. P. Fredman, Heat and Mass Transfer., 2003, 39, 285-295.

S3 T. Thorsen, S. J. Maerkl and S. R. Quake, Science., 2002, 298, 580-584.

S4 R. H. W. Lam, M.-C. Kim and T. Thorsen, Anal. Chem., 2009, 81, 5918-5924.

S5 A. P. Vollmer, R. F. Prostein, R. Gilbert and T. Thorsen, Lab Chip., 2005, 5, 1059-1066. 